\title{
IoT-Enabled Smart Sustainable Cities: Challenges and Approaches
}

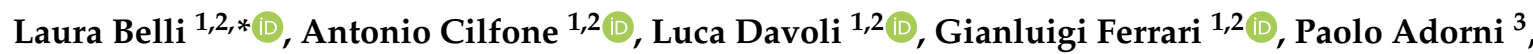 \\ Francesco Di Nocera ${ }^{3}$, Alessandro Dall'Olio ${ }^{3}$, Cristina Pellegrini ${ }^{4}$, Marco Mordacci ${ }^{4}$ \\ and Enzo Bertolotti ${ }^{4}$ \\ 1 things2i s.r.l., 43124 Parma, Italy; antonio.cilfone@things2i.com or antonio.cilfone@unipr.it (A.C.); \\ luca.davoli@things2i.com or luca.davoli@unipr.it (L.D.); \\ gianluigi.ferrari@things2i.com or gianluigi.ferrari@unipr.it (G.F.) \\ 2 Internet of Things (IoT) Lab, Department of Engineering and Architecture, University of Parma, \\ 43124 Parma, Italy \\ 3 BT Enìa Telecomunicazioni S.p.A., 43123 Parma, Italy; paolo.adorni@btenia.it (P.A.); \\ francesco.dinocera@btenia.it (F.D.N.); alessandro.dallolio@bt.com (A.D.) \\ 4 Comune di Parma, 43121 Parma, Italy; c.pellegrini@comune.parma.it (C.P.); \\ m.mordacci@comune.parma.it (M.M.); e.bertolotti@comune.parma.it (E.B.) \\ * Correspondence: laura.belli@things2i.com or laura.belli@unipr.it
}

Received: 8 August 2020; Accepted: 13 September 2020; Published: 18 September 2020

check for updates

\begin{abstract}
The ongoing diffusion of Internet of Things (IoT) technologies is opening new possibilities, and one of the most remarkable applications is associated with the smart city paradigm, which is continuously evolving. In general, it can be defined as the integration of IoT and Information Communication Technologies (ICT) into city management, with the aim of addressing the exponential growth of urbanization and population, thus significantly increasing people's quality of life. The smart city paradigm is also strictly connected to sustainability aspects, taking into account, for example, the reduction of environmental impact of urban activities, the optimized management of energy resources, and the design of innovative services and solution for citizens. Abiding by this new paradigm, several cities started a process of strong innovation in different fields (such as mobility and transportation, industry, health, tourism, and education), thanks to significant investments provided by stakeholders and the European Commission (EC). In this paper, we analyze key aspects of an IoT infrastructure for smart cities, outlining the innovations implemented in the city of Parma (Emilia Romagna region, Italy) as a successful example. Special attention is dedicated to the theme of smart urban mobility.
\end{abstract}

Keywords: smart city; internet of things; IoT; smart urban mobility

\section{Introduction}

In between the urban context and Information Communication Technologies (ICT), the term smart city is a relatively recent concept, whose diffusion has been rapidly increasing in the last years. Academic and industrial worlds, together with governments, institutions, and citizens, have coined several definitions for this emerging paradigm, which is now extremely popular and attractive. As an example, according to the authors of [1], a smart city could be defined as "a well-defined geographical area, in which high technologies, such as Information Communication Technologies (ICT), logistic, energy production, and so on, cooperate to create benefits for citizens in terms of well-being, inclusion and participation, environmental quality, intelligent development; it is governed by a well-defined pool of subjects, able to state the rules and policy for the city government and development." 
More recently, together with first attempts of practical implementations, the smart city concept has been accused of being often too technology-centric, mainly driven by technological companies' own goals, while lacking real attention to the municipality and people's needs. Therefore, this has led to a generalized need for a more sustainable approach.

Unlike the concept of smart city, sustainability has a long history (being first introduced in 1987) and has been widely accepted. It is based on three main pillars or aspects: social sustainability, environmental sustainability, and economic sustainability [2]. A more recent definition [3] describes a "sustainable city" as an entity for which the inflow of material and energy resources and the disposal of wastes do not exceed the capacity of the city's surrounding environment. More practically, in order to achieve this goal, the consumption of urban resources in a city should match-or not exceed — the quantity provided by the natural environment (e.g., soil, water, or energy resources). Moreover, pollution levels resulting from the city's activities should not overwhelm the environment's ability to provide resources to citizens and other members of the ecosystem [4]. Even if extremely simple and logical, the sustainability concept has been criticized for being, in some cases, outdated and not suitable for the needs of the highly digitized current society, characterized by extremely rapid change and growth.

As a consequence of these concepts' evolution, a new wave of academic discussions proposes a new paradigm, denoted as smart sustainable city, as a response to the current criticisms, proposing a more balanced approach. More in detail, this paradigm aims at combining urban sustainability and smartness of a municipality, focusing on the fact that both aspects should simultaneously be considered to provide the best "urban performance". A comprehensive definition [5] describes smart sustainable cities as "innovative cities that use ICT and other means to improve quality of life, efficiency of urban operation and services, and competitiveness, while ensuring that they meet the needs of present and future generations with respect to economic, social, environmental, as well as cultural aspects."

On the basis of these conceptual definitions, it is important to consider how a practical implementation of these concepts will affect the everyday lives of citizens. This is based on the new possibilities opened by the current wave of technological innovation and, more precisely, on the increasing adoption of devices and entities based on Internet of Things (IoT) technologies.

The IoT paradigm is one of the key aspects guiding the technological evolution and involvements in several scenarios and contexts, through a multitude of connected devices operating and cooperating in order to sense the physical world and adapt their behavior taking into account the changing context of the environment where they "live". Consequently, through the introduction of IoT innovation, smart sustainable cities can improve different aspects of their urban management (as shown in Figure 1), for instance, urban mobility, public transportation, e-governance, safety, security, public lighting, and environmental monitoring. The adoption of IoT technologies is expected to allow to monitor, control, and manage all the available resources, such as electric power, soil, water, people, and so on.

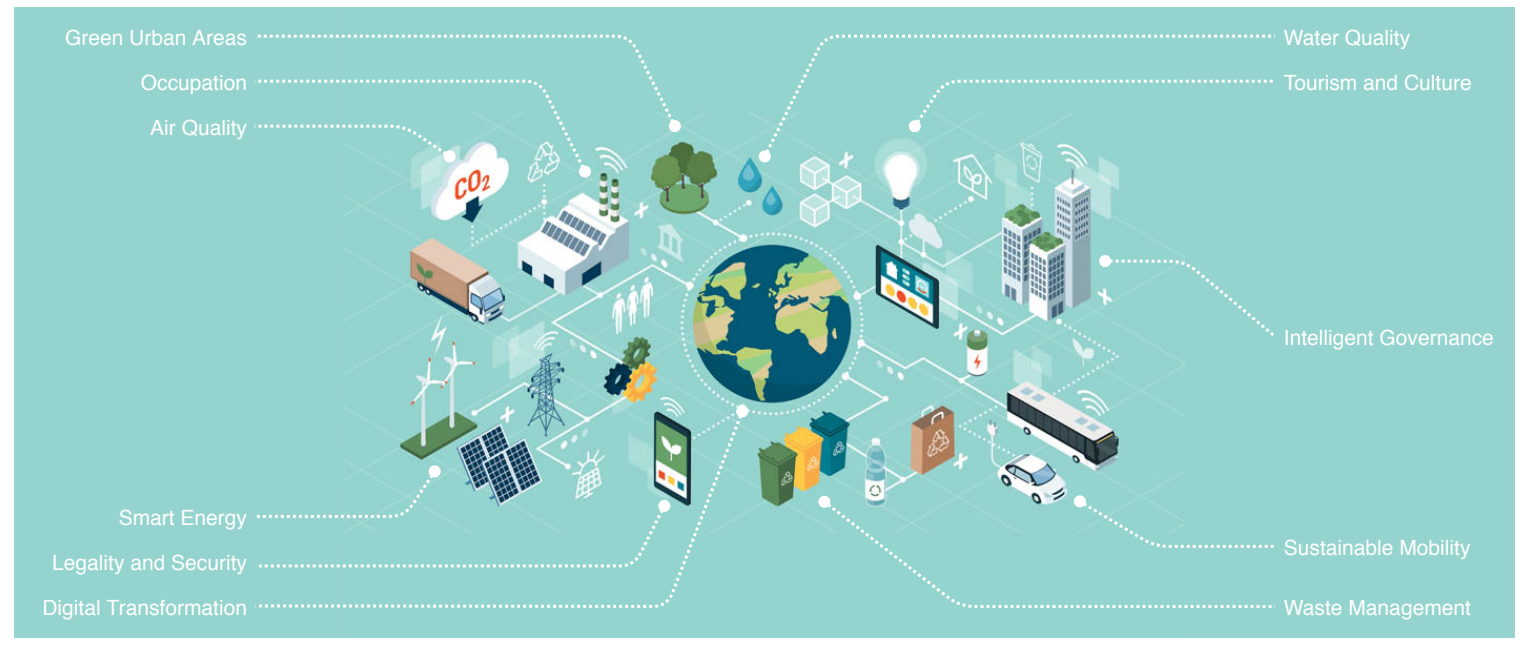

Figure 1. Key areas to deal with in a smart city. 
In order to reach these challenging objectives, the first step is represented by the definition and deployment of a reliable connectivity infrastructure that, in most cases, is supported by wireless networks - as they enable an information exchange with a more flexible and low-cost deployment than wired ones. Nevertheless, due to the complexity of sustainable smart city scenarios, in most cases heterogeneous communication technologies and different network architectures should be adopted, depending on the characteristics of specific services that need to be implemented (e.g., required low or high data bit rate), or operational constraints (e.g., the availability of a power source), the area to be covered (implying long-range or short-range communication links), and other aspects proper of the specific scenario to be dealt with.

After the deployment of a reliable connectivity infrastructure, which represents the backbone of an IoT-based smart city, it is possible to define the application level in different aspects of urban management, leading to the implementation of services of interest for citizens and institutions.

The aim of this paper is twofold: (i) we provide a review of the literature on smart cities, based on different indicators, and (ii) we address the main challenges and propose solutions related to the improvement of these indicators. Through the analysis of the existing literature, we identify the key challenges and propose IoT-based solutions on how a medium-sized city, such as the city of Parma, Emilia Romagna region, Italy, could improve the services offered to its citizens. In this way, we want to give a reference to researchers, companies, and institutions from different areas to suggest the main challenges that future smart cities have to face in different technological contexts, together with insights and references for smart cities' administrators, giving them the opportunity to better approach the technological revolution that will pave the way to the smart cities of the future.

The rest of the paper is organized as follows. In Section 2, we provide an overview on primary topics to be taken into account in a smart city, namely, the connectivity infrastructure and the set of indicators to be satisfied. Section 3 presents an overview of possible solutions which a municipality can introduce considering different application areas, with particular attention to the choices of the city of Parma. In Section 4, we deepen our analysis on the smart sustainable urban mobility topic, which represents one of the key evolution directions for the future of a smart city. In Section 5, an overview on global future research directions is discussed. Finally, in Section 6 we draw our conclusions.

\section{Overview on a Smart Sustainable City}

In general, a city, which aims at becoming a smart sustainable city, has to become more attractive, more sustainable, more inclusive, and more balanced for the citizens who live in, work in, and visit the city itself. To this end, a local administration-such as that of the city of Parma, located in the northeastern side of Italy and participating to the H2020 Ruggedised EU project [6]—could summarize its intentions with the following keywords;

- $\quad$ share experiences, information, and projects, as well as responsibilities, among citizens, stakeholders and other institutions, for all the decisions that will affect the life of people in the upcoming years;

- $\quad$ strengthen the identity of the city as a capital city for well-known aspects (e.g., good food, culture, and music), and make the city more attractive for its citizens, tourists, and businesses; and

- focus on values in terms of ethics, social responsibility, and quality of services for people and companies.

Therefore, the involvement of businesses, multi-utility companies, and public transport stakeholders can be considered as an essential added value to achieve these goals. To this end, a viable and optimal solution corresponds to creating inter-sectorial working groups from different areas (e.g., energy, urban planning, mobility, and ICT), working on integrating urban policies with the aim of evolving towards a smart city.

As an example, the following plans are associated with activities which a municipality may be interested in, in order to improve its sustainability level. 
- Strategic Environmental Assessment Plan (SEAP), targeting a reduction in $\mathrm{CO}_{2}$ emissions of a certain percentage, thus improving the global environmental conditions of the municipality.

- Sustainable Urban Mobility Plan (SUMP), aiming at

- reducing private cars' usage and allowing people to move in a more efficient, sustainable, and safe way;

- $\quad$ re-designing the public transport network to cope with actual user expectations in terms of efficiency, quality and fast access to information;

- developing inter-modality and interconnection with different urban transfer systems (e.g., bike and car sharing, electric mobility, car pooling);

- improving environmental quality, by reducing noise and air pollution, and recovering urban spaces; and

- reducing transport costs, energy consumption, and waste of resources.

- Sustainable Energy and Climate Action Plan (SECAP), aiming at (i) mitigating the environmental problems through decarbonization process, (ii) adapting to climate changes, and (iii) increasing energy efficiency for a secure and sustainable energy management.

\subsection{Connectivity Infrastructure}

As stated in Section 1, the IoT represents one of the core technologies for a smart city implementation, involving the deployment, in different urban areas, of an always growing number of heterogeneous connected devices, as shown in Figure 2, and representing an overview, made by IoT Analytics [7], on the estimated number of connected IoT devices (also denoted as Smart Objects) in the period $2015 \div 2025$. Following the increasing trend shown in Figure 2, it is clear that the communication infrastructure is the first key aspect to deal with in future smart cities, as connectivity in a smart city will be required anytime (day/night), anywhere (indoors, outdoors, or on the move), and between highly-heterogeneous entities (such as PCs, smartphones, tablets, battery-powered IoT devices, etc.) characterized by different communication needs and capabilities, and will involve Human-to-Human (H2H), Human-to-Thing, Thing-to-Thing, and Machine-to-Machine (M2M) interactions.

$\%$ IOT AN ALYTICS Insights that empower you to understand loT markets

\section{Global Number of Connected IoT Devices}

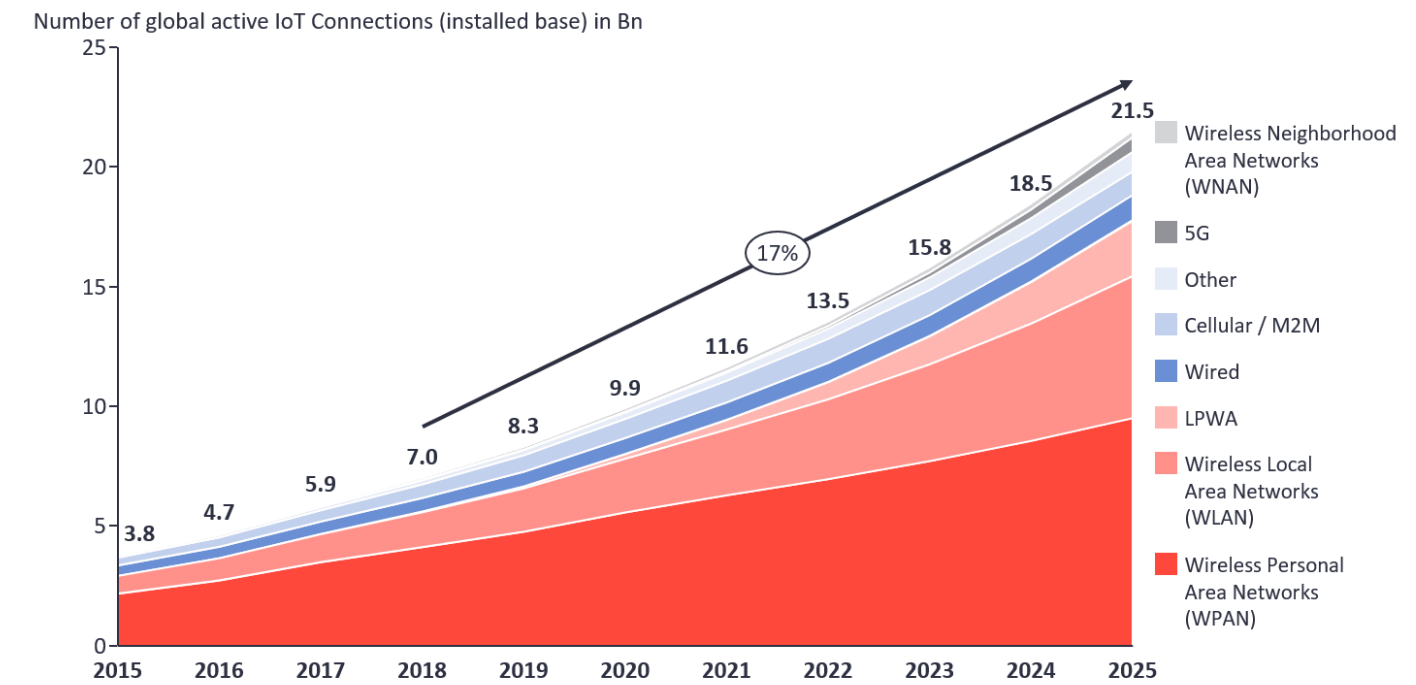

Note: IOT Connections do not include any computers, laptops, fixed phones, cellphones or tablets. Counted are active nodes/devices or gateways that concentrate the end-sensors, not every sensor/actuator. Simple onedirectional communications technology not considered (e.g., RFID, NFC). Wired includes Ethernet and Fieldbuses (e.g., connected industrial PLCS or I/O modules); Cellular includes 2G, 3G, 4G; LPWAN includes unlicen
and licensed low-power not proprietary networks with any range.

Figure 2. Trend on the global number of connected IoT devices in the period $2015 \div 2025$ [7]. 
Taking into account the different application scenarios, a heterogeneous set of communication technologies and different network architectures can be adopted guaranteeing connectivity, depending on the characteristics of the services to be implemented. In most cases, connectivity among IoT devices is guaranteed through wireless networks, enabling the exchange of information with flexible and low-cost deployments [8]. As an example, mesh networks and short-range communication technologies are preferable when end-to-end communications are not feasible because of power limitations or obstacles. In this case, hop-by-hop communications from device to device can be employed to bring information from IoT nodes (data sources) to data consumers (e.g., servers, border routers, etc.), and backwards. At the same time, star networks and long-range communication technologies are preferable in all the cases where direct and reliable communication links between a central "hub" and all IoT nodes within its coverage are available. The most relevant communication technologies that can be used in the smart city context [9] can be summarized as follow, with a corresponding graphical classification (in terms of transmission distance and communication speed) is shown in Figure 3.

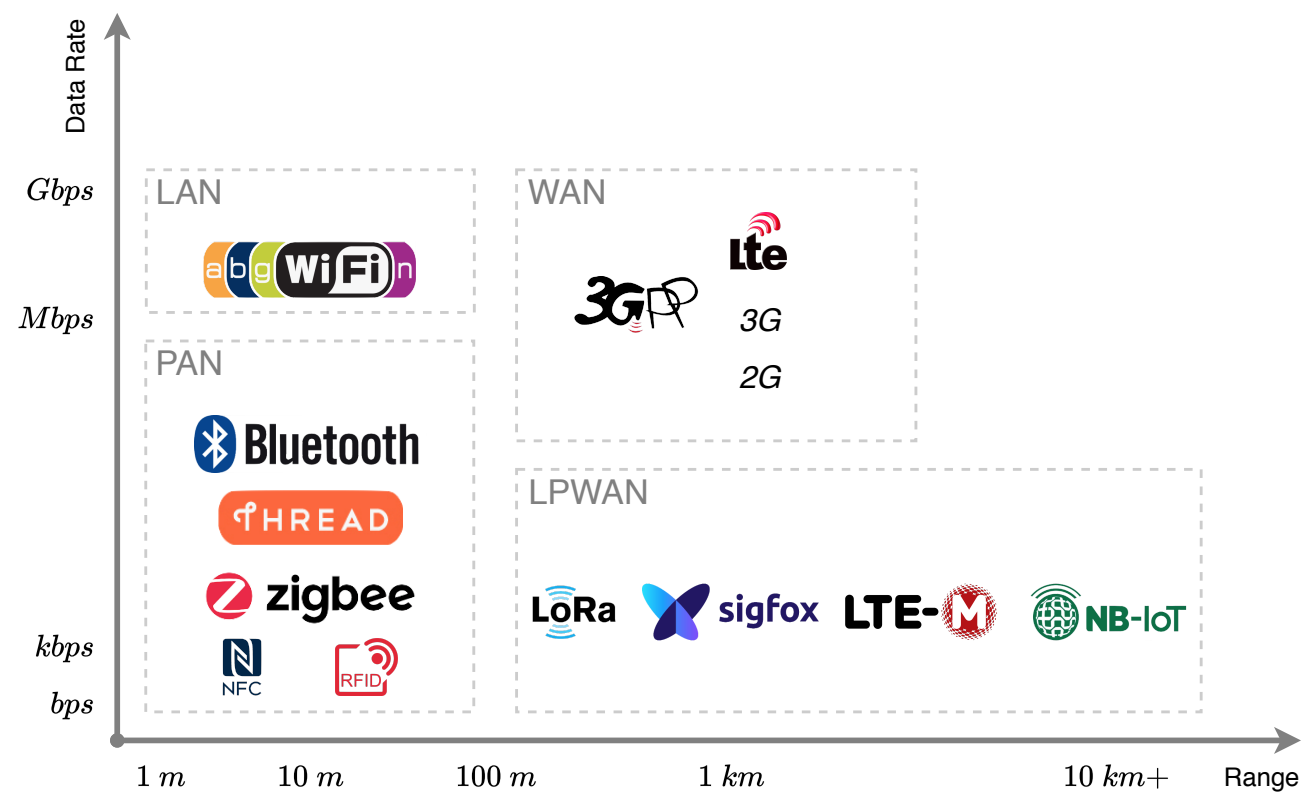

Figure 3. Network communication technologies.

- Low-Power Wide-Area Networks (LPWANs): This kind of network is especially designed to interconnect battery-powered devices with low bit rates over long ranges. Due to their low cost, wide coverage, and straightforward set-up, LPWANs are being deployed in different applications where a small quantity of data needs to be transmitted [10]. LPWANs work on both unlicensed and licensed frequency bands and include different standards (that can be open or proprietary), the most relevant ones are LTE-M [11], Narrowband IoT (NB-IoT) [12], and LoRa [13].

- 5G: Thanks to its advanced features, such as very low latency (less than $1 \mathrm{~ms}$ ) and very high bandwidth $(10 \mathrm{~Gb} / \mathrm{s})$, IoT is emerging as one of the primary use cases for $5 \mathrm{G}$. Therefore, $5 \mathrm{G}$ can be considered as an enabling communication technology for smart cities, allowing more and more IoT devices to be connected to the Internet, regardless of their location and time, supporting applications such as smart traffic systems, public safety, security, and surveillance in the context of smart cities [14].

- Wireless Local Area Networks (WLANs) and short-range networks: Many use cases in smart cities require the deployment of "regional" (namely, covering a limited spatial area) and, in some cases, of "individual" networks (such as Personal Area Networks, PANs). In this context, the available communication technologies are extremely diverse, spanning from protocols based on IEEE 802.15 to Bluetooth and Bluetooth Low Energy (BLE) [15]. 


\subsection{Sustainability Indicators}

As per definition [16], indicators can be described as "quantitative, qualitative or descriptive measures that enable information on a complex phenomenon, such as the dynamic urban environment, to be simplified into a form that is relatively easy to use and understand." Among their main functions (quantification, simplification, and communication), they show trends and changes in the measured phenomena, when periodically evaluated and monitored. Consequently, city indicators assist cities in setting targets and monitoring their performance over time and, at the same time, are also important in the municipality decision-making process. Recently, indicators are also employed by city management with the aim to increase transparency towards citizens through city dashboards showing real-time collected data which can be useful to citizens. Moreover, urban sustainability includes smartness indicators corresponding to tools that allow city planners, city managers, and policy-makers to estimate the socioeconomic and environmental impact of current urban designs, infrastructures, policies, waste disposal systems, pollution, and accessibility services by citizens. More in detail, they allow to detect problems and critical situations, identifying areas that would benefit from governance attention and technology-assisted responses. Finally, they allow cities to monitor the success and impact of sustainability interventions, while being extremely heterogeneous, and usually include aspects of sustainable development beyond environmental dimensions, such as public health and services, governance, income, business opportunities, and mobility.

On the basis of proper indicators, each a municipality should decide which would be the ones best addressing the needs and goals of their city, which would be easy to implement, and which would be worth the financial and human efforts. In some cases, a selection of different tools may be desirable for a city with a small population; in others, a large city may want to join an established global program of indicators. In [17], the European Community (EC) provides a short guide for local government actors to the currently available indicator tools for sustainable smart cities, focusing on the environmental dimension. Looking at this analysis, the starting point is that, in order to create a sustainable urban environment, it is crucial to measure and assess policies; infrastructure; socioeconomic factors; resource use; emissions; and any other process that contribute to and profit from the city's metabolism, prosperity, and quality of life [18]. This will allow governments to identify areas of opportunity as well as concerns, and to respond by developing realistic sustainability goals with a long-term perspective.

In order to choose the right sustainability indicator, it is important to understand the various purposes which indicators can be used for. Fundamentally, they can be applied in three ways:

- explanatory indicators, corresponding to a well-defined set of indicators collected in order to evaluate the current state of the environmental dimension of sustainability in a city or urban area;

- $\quad$ pilot indicators, referring to indicators chosen specifically to assist policy-making; and

- $\quad$ performance assessment indicators, which are the most common ones and generally involve Key Performance Indicators (KPIs).

Data availability is another aspect to be carefully considered when selecting indicators, as without good data-collected through proper monitoring-it is not possible to develop indicators. Moreover, as indicator sets must reflect the geographical and social context of the urban area they have to describe, they should be locally relevant and suitable for the scale (in terms of size, physical layout, and organizational structure) of the specific city or municipality.

As a further example, in [19] the problem of the most suitable indicator framework's choice for the smartness level of a municipality is analyzed and accompanied by a taxonomy, shown in Figure 4, to compare smart sustainable city indicators according to their conceptual urban focus (e.g., types of urban smartness and sustainability), relevant application domains (energy, transport, ICT, economy, etc.), and types of indicators (input, process, output, outcome, impact). 


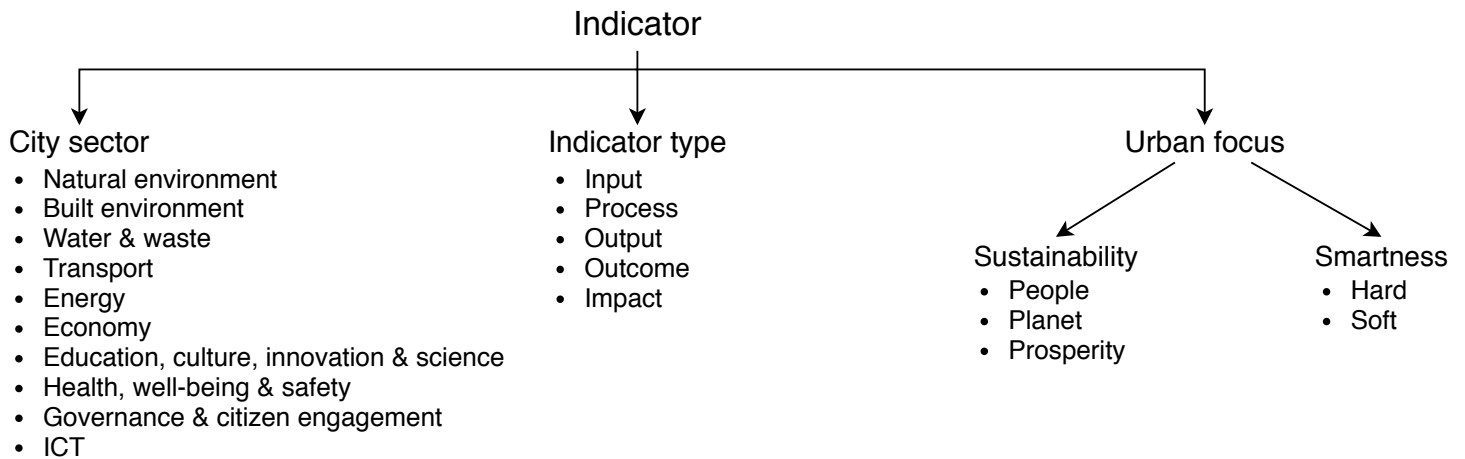

Figure 4. Taxonomy indicators used to decide the smartness level of a municipality.

\subsection{Smart City Challenges}

As highlighted in Section 2.1, orchestrating the smart city ecosystem requires the use of technology as a basic ingredient, as well as to take into account social and human capital aspects. Nowadays, there are many smart city deployments based on custom systems and solutions, but these are not always suitable to other cities around the globe and, sometimes, only a subset of the various aspects needs to be considered. In the following, the main barriers, issues, and open challenges identified in the literature [20] for smart cities are summarized. More in detail, we identified that these challenges can be divided within four main dimensions, as shown in Table 1: citizens, mobility, governance, and environment.

Table 1. Smart city challenges.

\begin{tabular}{|c|c|c|c|}
\hline Citizens & Mobility & Environment & Governance \\
\hline $\begin{array}{l}\text { - Unemployment } \\
\text { - Social cohesion } \\
\text { - Poverty and inequality } \\
\text { - Aging population } \\
\text { - Data safety and privacy } \\
\text { - Urban violence } \\
\text { and insecurity } \\
\text { - Shortage in access } \\
\text { to technology } \\
\text { - Health and } \\
\text { emergency management } \\
\text { - Deficit of social services }\end{array}$ & $\begin{array}{l}\text { - Sustainable mobility } \\
\text { - Inclusive mobility } \\
\text { - Multimodal } \\
\text { transport system } \\
\text { - Interoperability } \\
\text { - Traffic congestion } \\
\text { - Alternative mobility } \\
\text { - Lack of public transport } \\
\text { - Weak ICT infrastructure } \\
\text { - Pollution }\end{array}$ & $\begin{array}{l}\text { - Energy saving } \\
\text { - Holistic approach to } \\
\text { environmental and } \\
\text { energy issues } \\
\text { - Climate change effects } \\
\text { - Rapid population } \\
\text { growth } \\
\text { - Energy resources } \\
\text { scarcity } \\
\text { - Water scarcity } \\
\text { - Pollution }\end{array}$ & $\begin{array}{l}\text { - Flexible governance } \\
\text { - Territorial cohesion } \\
\text { - Interoperability } \\
\text { - Combination of } \\
\text { formal and informal } \\
\text { government } \\
\text { - Gap between citizens } \\
\text { and government } \\
\text { - Unbalanced urban } \\
\text { development } \\
\text { - Deficit of social services } \\
\text { - Unemployment } \\
\text { - Sustainable economy } \\
\text { - Weak ICT infrastructure } \\
\text { - Shortage in access } \\
\text { to technology }\end{array}$ \\
\hline
\end{tabular}

From the citizens' point of view, the design of a smart city should take into account people's quality of life, with particular attention to the privacy problem when personally identifiable information and household-level data about citizens are involved. This is notably important as citizens might fear the introduction of innovative technologies [21,22] or might perceive it as intrusive. Another important aspect is the equity, meaning that all members of the community should benefit from smart city technological improvement and, more in general, no urban areas should be marginalized, aiming at reducing the gap between rural and urban areas.

Considering the governance dimension, the smart city concept requires a change in government models, in order to be more flexible and to combine institutional policies with bottom-up initiatives, improving and promoting territorial cohesion, collaboration, and communication between different 
entities, thus avoiding the spreading of multiple similar initiatives, not working together in the most efficient way [21].

In the literature, the mobility dimension is recognized as one of the most relevant aspects considering smart city deployment, with the aim of providing a sustainable, inclusive, and efficient mobility system for both goods and people in the urban area.

Another dimension, not yet fully investigated in the literature, pertains to environment-related aspects in the design of smart city services, including efficient and sustainable resources management (such as water and energy), pollution, and, in general, the impact of urban activities.

Finally, a relevant cross-dimensional aspect that is considered as a possible barrier to smart city development is interoperability, as currently deployments are often based on proprietary and isolated solutions. Instead, to this end, open standard-based devices have to be used at all levels, in order to obtain economical scale and optimize the results. From a software interoperability point of view, a coordination between data collection and analytic processes across different system is also required.

\section{Improving the Sustainability of a Smart City}

\subsection{An Illustrative Smart City: Parma}

Besides the guidelines on indicators sets provided at European level, each country performs its own analyses and reports to measure and estimate the level of smartness and sustainability of different national cities. Therefore, an ever-increasing number of municipalities are selecting their own indicator sets, aiming at finding the key aspects in their evolution towards sustainable smart cities. An example of a medium-sized city is Parma, Italy, that, from 2017, ranks in the top 10 Italian cities according to the iCityRank ranking [23].

The iCityRank national ranking aims at giving a measure of the progresses of different Italian municipalities towards the objective of being a smart city. In order to quantify this progress, proper performance metrics include dynamism, functionality, attention to ecological problems, sustainability, attention for citizen, and others. This progress is obviously supported by the possibilities opened by technological advances technological advances. Ranking is based on several indicators, which change and are re-evaluated every year, that are related to different aspects of the quality of urban life. In 2019, the indicators selected by iCityRank were the following, as shown in Figure 5.

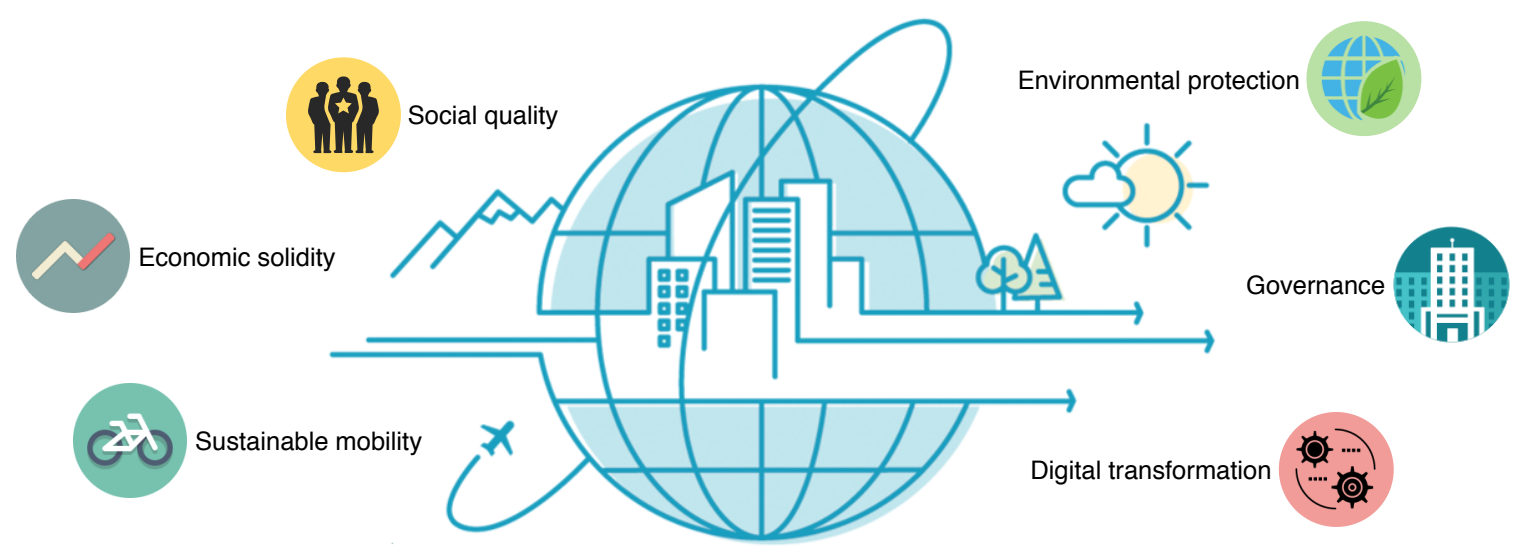

Figure 5. Smart city indicators selected by iCityRank in 2019.

- economic solidity;

- $\quad$ sustainable mobility;

- environmental protection;

- social quality;

- governance;

- digital transformation. 
For each one of these indicators, the annual report presents a separate ranking, which is evaluated considering a set of more than 100 sub-indicators, in turn measuring more than 250 sub-indicators coming from qualified sources or specific surveys.

In Table 2 , the ranking obtained in the period $2017 \div 2019$ by the city of Parma is shown: the data trend clarifies how the municipality of Parma is working on different aspects with the clear intent of improving the services offered to its citizens by implementing the concept of smart sustainable city.

Table 2. Ranking of the city of Parma, Italy, from the iCityRank report, for the period $2017 \div 2019$.

\begin{tabular}{|c|c|c|c|c|c|}
\hline 2017 & & 2018 & & 2019 & \\
\hline Indicator & Rank & Indicator & Rank & Indicator & Rank \\
\hline General & 9 & General & 8 & General & 8 \\
\hline Poverty & 1 & - & - & \multirow{4}{*}{ Economic Solidity } & \multirow{4}{*}{$\varepsilon$} \\
\hline Economic Growth & 19 & Economic Development & 14 & & \\
\hline Employment & 11 & Work & 7 & & \\
\hline Research and Innovation & 26 & Research and Innovation & 20 & & \\
\hline Water and Air & 64 & Water and Air & 102 & \multirow{5}{*}{ Environmental Protection } & \multirow{5}{*}{18} \\
\hline Energy & 50 & Energy & 23 & & \\
\hline Waste Management & 12 & Waste Management & 10 & & \\
\hline Soil and Territory & 4 & Soil and Territory & 1 & & \\
\hline Urban Green Areas & 67 & Urban Green Areas & 86 & & \\
\hline Culture and Tourism & 27 & Culture and Tourism & 26 & \multirow{3}{*}{ Social Quality } & \multirow{3}{*}{9} \\
\hline - & - & Social Inclusion & 1 & & \\
\hline Education & 31 & Education & 9 & & \\
\hline Digital Transformation & 22 & Digital Transformation & 9 & Digital Transformation & 8 \\
\hline Sustainable Mobility & 8 & Sustainable Mobility & 13 & Sustainable Mobility & 12 \\
\hline Legality and Security & 64 & Legality and Security & 22 & \multirow{2}{*}{ Governance } & \multirow[b]{2}{*}{7} \\
\hline Governance and Participation & 7 & Civic Participation & 13 & & \\
\hline
\end{tabular}

In order to improve the rankings shown in Table 2, within the Ruggedised project [6] the city of Parma has created a local Smart City Governance Plan, acting as a promoter within the city and the stakeholders, with the goal of developing a vision, a roadmap, an investment plan, and an action plan. In November 2017, the initiative Parma Futuro Smart [24] was officially launched to co-design and co-manage the smart city process. In detail, Parma Futuro Smart is a political strategy tool that supports the city's decisions for the definition of a smart city's Action and Investment Plan by 2030. With its specific connection and promotion role, more than 50 local, regional, and national stakeholders have been involved in this initiative (such as public authorities, research institutes, private enterprises and representatives of associations, non-governmental organizations, and citizens). The concept of smart city promoted by Parma Futuro Smart does not mean merely innovation, resilience, and technology, but also dialogue, social inclusion, sustainability, creativity, and identity. Therefore, the ultimate goal is to create a "humanized" and structured city based on a strong local network composed of people, places, and policies. From an organizational point of view, the local stakeholders involved in the foresight process have been divided into the following four thematic working groups, with each of them being linked to one or more specific Sustainable Development Goals (SDGs):

- Smart transport and mobility;

- Smart energy, environment and smart grid, infrastructure;

- Smart society and people;

- Smart economy and innovation. 
Then, these SDGs have been deeply discussed during workshops and, as a result, different perspectives and ideas have been collected, processed, and consolidated into the definition of a comprehensive and shared smart city vision. More in detail, the Parma Futuro Smart initiative has been structured into the following series of events.

- $\quad$ Kick-off and Brainstorming World Café for Parma Futuro Smart (30 November 2017).

- Scenario-Vision Workshop (6 April 2018).

- From Scenarios to Roadmap Workshop (9 November 2018).

- Co-creation Workshop with the thematic groups (6 August 2020; 8 September 2020; 15 September 2020; 30 September 2020; 14 October 2020).

- $\quad$ Presentation of the Smart City Governance Plan (planned at the end of 2020).

These topics have been also included in the Smart City Protocol signed in May 2019 to formally engage nearly 40 stakeholders and create a cooperation platform to share projects and competences with the ultimate goal to firstly build a smart community to become then a smart and green city.

Thanks to the participatory foresight process of Parma Futuro Smart, supported by the Ruggedised EU project, the city of Parma sets the goals for the next decade. The administration has decided to accelerate the process to fully turn Parma into a green city and the Smart City Action and Investment Plan (SCAIP) will be totally consistent with these goals and will help to achieve them. Parma pursues the farsighted goal to become a green city, based on the most crucial aspects of environmental quality: efficiency and circular use of resources, and mitigation and adaptation to climate change, enhancing the economic and social implications of a better quality of life and well-being at the urban level generated by a green economy. This view is also reflected in the 5 core pillars of the infrastructural and urban development planning of the city, a city without suburbs, with the aim to sew up the urban fabric, as follows.

- Urban regeneration of the existing city, through economic incentives and regulations that guide the market towards the improvement to extant buildings, avoiding any further soil sealing. The plan also identifies 15 strategic areas of urban regeneration.

- Reduction of land sealing, transforming of 4.3 million $\mathrm{m}^{2}$ wide land initially classified to be used for building purposes into agricultural land and enhancing the agriculture and the environment through the transformation of up to 435 hectares of potentially building areas into agriculture land or natural parks, finally creating the Periurban Agricultural Park.

- Hydraulic and geological land safety, assuring the security of the territory and citizens through the Hydraulic Risk Management Plan and Seismic Micro-zoning Plan.

- Widespread service network, with several socialization places dedicated to culture and sports, to promote the quality of relationships between citizens, civic awareness, social inclusion, and perceived safety, particularly in suburbs.

- Facilitating the birth of centers of excellence, by multiplying the opportunities and maintaining high local production competitiveness and the strategic assets of Parma, such as trade fair, university, manufacturing, tourism, and agro-industry, also through city facilities well connected with transport infrastructure.

Besides this co-creation work, Parma has also started a wide program of technological innovation of the municipal services, and implemented several innovative ICT projects, examples of which are listed as follows.

- $\quad$ Centralized control of traffic lights: The municipality sets up a light intersection management system in order to maintain a good coordination of the traffic lights in the urban area (algorithmic optimization) and regulate the duration of green lights depending on the intensity of the traffic.

- $\quad 3 D$ RTE Parma Information Management: The Civil Protection department of the municipality of Parma has developed a geo-cartographic software for planning, managing emergencies, and for 
supporting decisions during critical phases. This software is linked to the Geographic Information System (GIS) of the municipality and uses a Global Positioning System (GPS) and a digital modeling. It contains different kinds of data, ranging from existing infrastructures to old people served by the municipal social services. The geo-cartographic core is the basis on which a whole series of services and functionalities can be implemented. The purpose is to share all the information already held by the municipality, that now stand in different departments. Moreover, this will ensure the full operation in terms of better knowledge, integration, and protection: this will improve the management and planning of the city and its resilience during critical events.

- Smart public lighting: Due to a refurbishment plan of the public lighting network of the city of Parma approved in December 2017, the urban lighting redevelopment plan involves a radical modernization of the city network, replacing the old systems with new LED-based ones. This allows a smart management and the installation of new surveillance and traffic control cameras and new sensors. Among a total of 36,613 lighting points, approximately 24,000 new LED lighting systems have been installed, with a linear network extension of $35 \mathrm{~km}$. The project will end in 2035, with a total investment of $29 \mathrm{M} €$ (the contract has been already signed by the municipality).

- Traceability of bike sharing flows: The municipality runs a pilot project putting smart locks on 40 items of the bike sharing fleet, in order to monitor bike flows. In the future, a dedicated app will be developed for for the bike sharing system. At the moment, the city of Parma has 26 bike sharing stations and this service is widely used, in particular by commuters, students, or tourists. The main goal of this activity is to have an overview on how the bike sharing service is used and to evaluate if it is better to put some new bike sharing stations or it is more convenient a mixed system, with fixed stations and free floating.

- $\quad$ Radio-Frequency IDentification (RFID) access management: In 2019, the city of Parma decided to introduce IoT-based technological advancements to the existing mobility services, in order to provide a better experience to users. The city of Parma dematerialized the permits to access the city center of cars and logistics operators. The traditional paper permit has been replaced with a new, technologically-advanced pass, equipped with a microchip with RFID technology, which represents a sort of digital identity of the vehicle, that in the future will be used also for different purposes. The pass will be indeed enriched with new services related to the world of mobility, such as easy parking, "alert system" communications, and much more. The new electronic pass, created with the aim of simplifying, speeding up and facilitating the procedures for issuing and renewing permits, has allowed the complete dematerialization and automation of transit and parking permits in use.

Moreover, the municipality of Parma recently planned various deployments in different areas of the city, in order to actuate several IoT-aided actions for monitoring different aspects of the daily life of its citizenship. In detail, the city is providing with a LoRaWAN coverage through six $868 \mathrm{MHz}$ LoRaWAN-powered GateWays (GWs), able to potentially manage 10k+ LoRaWAN-equipped devices, thus enabling the use of this kind of wireless network onto the city limits (in free space, these GWs will be able to cover an area with a radius of approximately $10 \mathrm{~km}$ ). Thanks to this ongoing network coverage activity, provided by the company BT Enìa, the municipality of Parma, in collaboration with other research and industrial entities of the territory, deployed the following IoT-oriented kind of devices.

- Magnetic parking sensor (drowned in parking stalls): this sensing node is able to detect the parking lot's status change (free-to-busy, busy-to-free).

- Vehicle passage counting sensor: this sensing node returns the amount of vehicles transited bidirectionally, on a predefined time interval, along the road in which it has been mounted.

- Sensor for waste bins status monitoring: this sensing node is able to collect information about the bins filling level (based on 4 thresholds) together with a timestamp of the event, thus providing 
various additional estimations (e.g., time percentage in which the waste bin has been filled on a certain level, as well as full, average filling level in a certain city zone, and emptying frequency and last emptying).

- Sensor for counting the passage of people: this sensing has been used to estimate the average statistical amount of people passed in front of the sensor itself, on a predefined time interval, thus returning a statistical analysis on pedestrian traffic, and in case of unpredicted events (e.g., in case of crowed events), properly reroute people masses on less crowded areas.

- Environmental sensor (temperature, humidity, and pressure measurement): this sensor node is able to return the current environmental situation, while its data can be used as support to other sensing nodes, fusing together these estimations.

- Smart parking sensor based on optical technology: this sensing node is able to retrieve the status of different parking stalls in a monitored parking area with a timestamp.

- Sensor for measuring the environmental acoustic pressure: this sensing node is able to retrieve the average acoustic pressure level (dimension: $[\mathrm{dB}]$ ) on a predefined time interval, thus providing an alert in case certain unpredicted events happen (e.g., intense traffic, road construction sites, etc.).

As mentioned before, these heterogeneous IoT devices provide different kinds of services and have been deployed in different areas of the city of Parma, as shown in Figure 6.

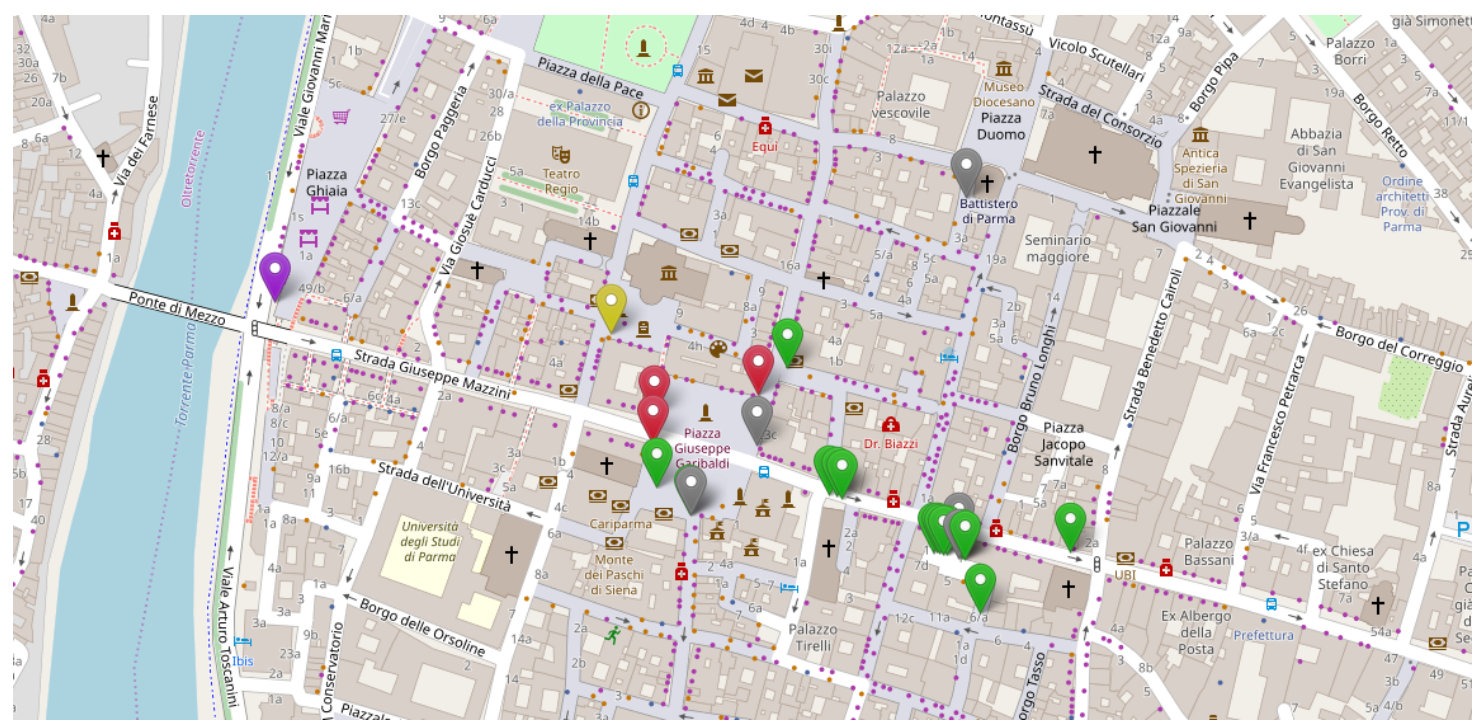

Figure 6. Smart objects locations in the Proof of Concept (PoC) made by the municipality of Parma in collaboration with research and industrial entities of the territory.

The improvements achieved in the city of Parma show that the technological advances observed in the last years in the field of IoT-thanks to the efforts of different subjects such as academia, research centers, innovative spin-offs, and start-ups_are enabling the implementation of a smart city [25], thanks to the fact that each of the indicators shown in Table 2 can be, in different ways, affected and improved by IoT-oriented technologies.

In the following, we discuss on how IoT can be beneficial for a city, considering a subset of the previously mentioned indicators.

\subsection{Sustainable Mobility}

One of the sectors that historically drives important aspects for growth and progress in the cities is mobility, which allows people to move from one place to another and boosts knowledge growth, including the adoption of modern technologies in different contexts [26].

In this regard, by embracing the adoption of sensing mechanisms in the context of the mobility, cities will improve the quality of life of their citizens and the quality of the services offered to the 
whole community, also by a rationalization in the use of the city's resources [21]. In fact, the adoption of sensors allows a city (with the objective to become "smart") to set up heterogeneous and complex scenarios integrating sensors/actuators in an overall and complex "virtual environment" in turn involving Big Data, Machine Learning (ML), and further technologies and paradigms [27].

If properly considered and designed, most of the smart city solutions can target different aspects of the infrastructure to improve the sustainability of their services [28], as highlighted in Figure 7. Nowadays, this is even more true in the case of traffic handling in sustainable mobility scenarios, due the strong relation between traffic and communication systems and due to the fact that the infrastructure is often stressed to its limits, in order to give citizens the best available service. Because of this, it is essential to think about alternative solutions, such as dynamic paths and routes, and more optimized/efficient transportation systems, bringing in the concept of ITSs. Examples of these renovated technology-aided mobility paradigms involve smart traffic planning and innovative public transport systems, which are even more central for an interconnected infrastructure.

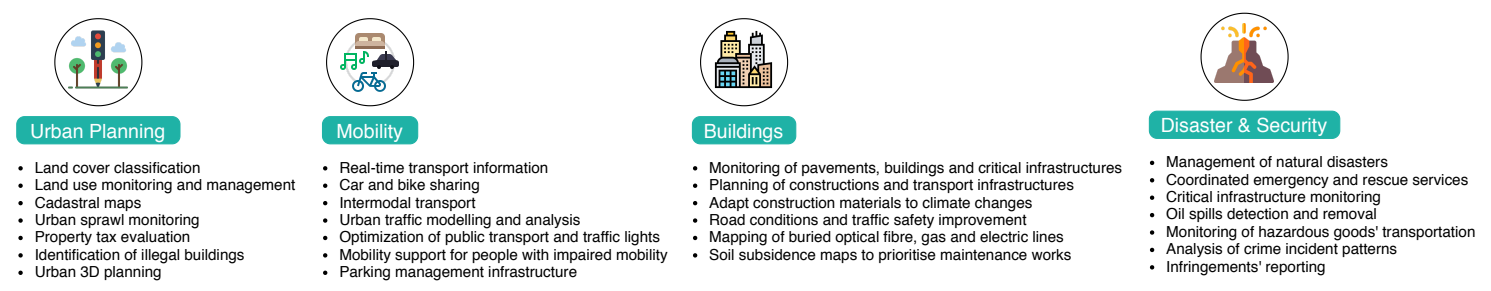

Figure 7. Smart city areas involving urban planning, mobility, building, and disaster and recovery.

Finally, in order to improve the smartness of a city and enable municipality operators to support citizens in their daily activities, a set of heterogeneous and integrated tools, applicable to different scenarios in a smart and integrated way, are needed in order to provide mechanisms to sense the status of the city, to drive the data in a singular or aggregated way, and to provide a set of tools for data analysis to data scientists [29]. To this regard, a smart city platform should be capable to inform both city users (citizens, students, commuters, workers, etc.) and city operators, to collect their feedback about city infrastructures and services, providing to the citizens an integrated info-portal for ad hoc and personal visual applications (i.e., multi-platform dashboards) and providing to the platform's managers a way to monitor the functionalities of the sustainable mobility infrastructure. To this end, a more comprehensive discussion on how IoT-oriented solutions can be useful to enhance the smart sustainable mobility aspects of a city candidate to become a smart city; this is performed in Section 4 .

\subsection{Occupation}

By analyzing a city from a social point of view, with regard to the occupancy level, it is well known that a high concentration of skilled and well-prepared workers can promote the spreading of knowledge (i.e., creation, diffusion, acquisition, and accumulation) among people (individual workers), places (geographic spaces), and time. To this end, workers can certainly benefit from their closeness to a labor-skilled, dense job market in which, through different (traditional and modern) channels, they can learn from other workers [30].

These job market's preconditions, called human capital effects [31,32], have historically driven the evolution of cities [33,34] and the urban endogenous growth [35,36], and provides a first evidence on how human capital effects mostly affect workers in the same industry and city through face-to-face interactions $[37,38]$. Nevertheless, this is even true from one firm to another one nearby within the same industry in a city $[39,40]$, as shown in Figure 8. 


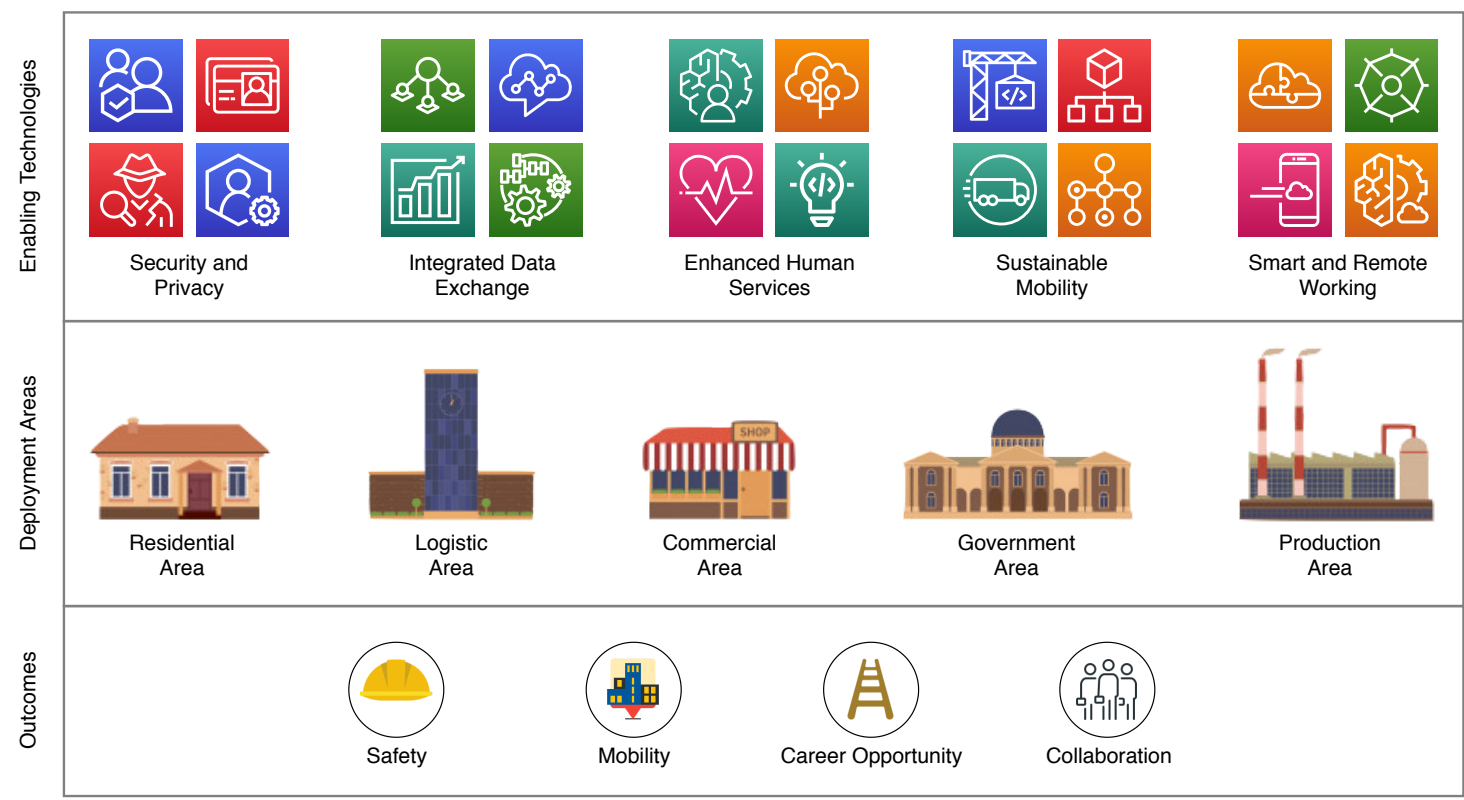

Figure 8. Outcomes and enabling technologies to be considered in a smart city deployment, with regard to the occupation indicator.

This leads to the fact that (typically) the more densely concentrated a job market is in a limited geographic area, the higher the chances workers will have in their "random" matches and interactions, due to the density of a local job market. Nowadays, the importance of job market density at urban levels is that workers can socialize more frequently and build social networks more easily, in order to exchange information and look for new job opportunities [41]. Moreover, this is confirmed by the fact that social interactions among neighbors help workers to build informal hiring networks, which have a significant impact on a wide range of job market outcomes [42]. If aided by modern technologies (e.g., IoT-oriented technologies), workers living in smart cities will benefit from different sides with regard to their working life, for example, in the way they can reach their workplace in less time and with shared transport vehicles. Another aspect which can be enhanced and improved in the occupation field, by the adoption of IoT-oriented solutions, regards the safety of workers in their workplaces, and this can be perceived by workers on both passive and active sides. In the passive case, this is accomplished by providing production plants, as well as commercial offices, with IoT devices monitoring the working conditions and the environment in which they are performing their job, and thus reporting these surveys to company's control centers, as well as proactively reacting in order to avoid dangerous situations inside the plants themselves. Instead, IoT-oriented active devices can be worn directly by the workers, and monitor their daily activities, thus actively aiding each worker's job (e.g., driving them inside a plant in order to reach, in a reduced time, a target department with a forklift) as well as monitoring their stress levels and reporting abnormal situations to the internal company's medical team.

\subsection{Waste Management}

An aspect which municipalities have always to care about is related to the waste management, leading to both private and public waste harvesting. Considering this topic, city operators often tend to outsource the waste management service to external companies, thus leaving these companies billing citizens based on different parameters.

From the municipality point of view, waste management can represent an interesting aspect which can contribute to the evolution towards a smart city, as it has the potential to be enriched by IoT-like technologies and, thus, to offer citizens an improved service [43]. In detail, the municipality can make an agreement with these private (as well as subsidiaries) companies in order to equip each 
waste basket with some IoT monitoring devices, then being able to remotely collect information from each basket. Thanks to these deployments, it is possible to perform several tasks in different contexts. As an example, as shown in Figure 9, the municipality can optimize the waste harvesting service, balancing resources (i) in the presence of unplanned events (e.g., fairs, music concerts, etc.), (ii) during time slots that less affect the community, and (iii) only emptying baskets that are effectively full $[44,45]$. Moreover, this improved waste harvesting service, aided by IoT-oriented solutions, can be applied directly on the waste bins, as well as exploiting optical technologies to determine the amount of waste poured into the bins by estimating the waste's volume and, based on the target bin, its overall volume. Therefore, by applying data fusion and analyzing the collected data, the municipality can select the best strategy to be applied.

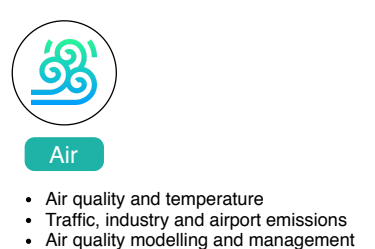

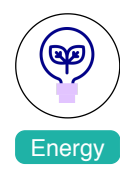

- Solar energy systems' assessment

Wind maps for wind power stations - Synchronized power grid systems
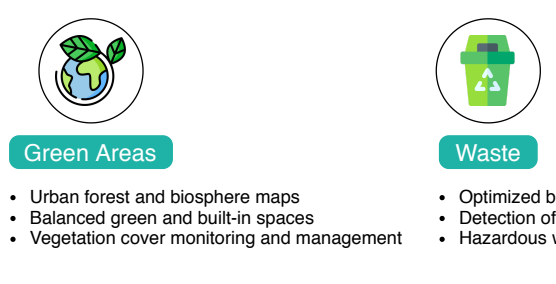

- Optimized bin collection Detection of illegal dump sites - Hazardous waste tracking

Figure 9. Smart city areas involving air, energy, green areas, and waste management.

\subsection{Digital Transformation}

From a general point of view, a digital transformation process can be described as " $a$ change in the internal mechanisms of an organization, intended to provide a new (or significantly better) products or services supply, by using information technology as key enabler" [46]. According to this definition, a smart space, involving an interaction among humans and technology-enabled systems in a physical or digital environment, can be enhanced and become intelligent following different key dimensions [47], identifying the directions that a smart city should follow in order to shift from being an isolated environment to an intelligent municipality [48,49].

As already mentioned before for other indicators, devising a smart city should inevitably improve the life quality of citizens, maybe through the use of IoT-oriented technologies [50], thus increasing the efficiency of services and including efforts to make the best use of existing resources (e.g., managing food production, congestion, and pollution) [51,52].

A key point of the digital transformation process proper of a smart city is further related to the need to be able to collect data produced by heterogeneous sources (e.g., data streams from bicycle sharing schemes, car parks, air quality sensor data, etc.) [53,54], and analyze them in a close-to-real-time way [55,56], so that city planners can employ up-to-date predictive models and use them in planning activities. It is noteworthy that citizens should actively exploit opportunities for growth and development, too, through appropriate policy implementation, human capital development, and developed culture of innovation [57].

\subsection{Tourism and Cultural Aspects}

Modern cities are nowadays facing great challenges, especially in the context of emerging economic tendencies (e.g., the rising importance of cultural values in urban systems), demographic transformations (rural-urban and people migration), and environmental concerns (climate change and pollution) [58]. These challenges, reinterpreted in a constructive way, represent not only powerful engines for economic development and technological progress, but also effective magnets for visitors [59], as shown in Figure 10. 


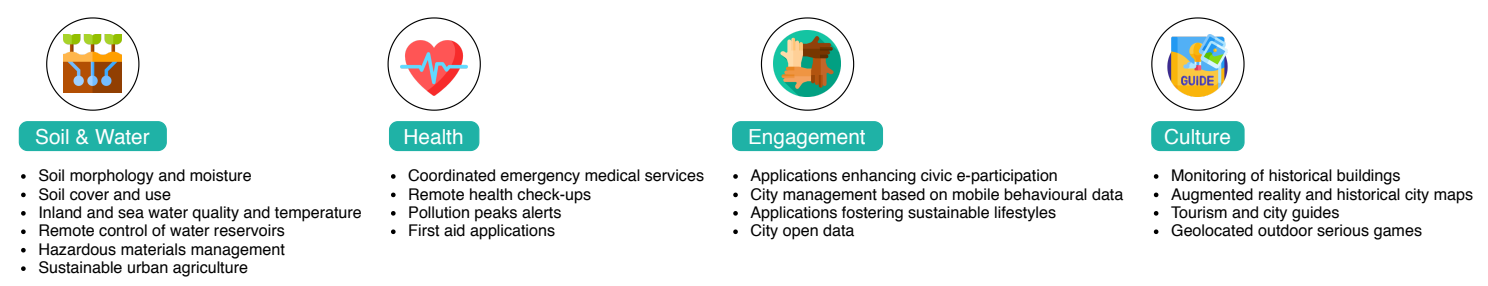

Figure 10. Smart city areas involving soil and water, health, engagement, and culture.

With regard to tourists visiting a city with cultural ambitions, the creative elements guiding several aspects of a municipality (e.g., innovation, knowledge exchange, cultural interaction, artistic production, etc.) have received particular attention, enriching the interest in cultural heritage and its relationship with local economic development $[60,61]$, while it has to be highlighted that diverse types of creative activities have a certain impact on satisfaction and motivation of tourists $[62,63]$. In detail, within a city, urban mass tourism is usually driven by various attractions and services designed to satisfy the preferences and interests of the average citizen vising the city $[64,65]$. This means that the tourism concept can be seen as a location-based activity involving the knowledge-based attitudes of the visitors [66], while urban mass tourism can be described as characterized by (i) different forms of direct and indirect interactivity between the municipality and people (i.e., tourists) living the city itself $[67,68]$, and (ii) consumption, production, and supply of tourism-oriented services occurring in different municipal areas [69].

Consequently, the large amount of information that can be produced by tourists moving inside the city, in combination with the importance of cultural activities and heritage, enhances the potential for the implementation of location-based and knowledge-based innovation strategies. IoT technologies play a key role in these contexts, as they allow to increase the interaction between data consumers, data producers, and municipality leadership $[70,71]$, through permanent collaborative processes and participatory governance [72,73]. Moreover, tourists act more and more as creators of multimedia contents produced and shared through social networks [74]. In turn, this could be exploited by an IoT-based smart city architecture.

A smart city-oriented tourism development should also take into account-both as a general concern and in the way IoT-oriented technologies may intervene-the way in which conflicts and tensions should be identified and solved (e.g., caused by a cumulative use of urban resources by residents and tourists, scarce public spaces, and potential overuse of infrastructures and facilities) [75-77]. Finally, according to the United Nations World Tourism Organization (UNWTO) [78], there will be increasing importance placed upon flexible urban tourism products and services for contemporary tourism dynamics, as tourism's vitality will guide new changes in the urban landscape, personal relations, and job creation (as discussed in Section 3.3), thus supporting the maintenance of urban infrastructures and public services.

In fact, thanks to the large number of embraced aspects, tourism and culture can be certainly enhanced by means of IoT-oriented solutions. As an example, tourists can be provided with a mobile App exploiting several technologies on the mobile device during a tourist trip, such as (i) rear camera, for Augmented Reality (AR) on the artworks, and frontal camera, for emotional analysis, when visiting an exhibition; (ii) Near Field Communication (NFC), for paperless ticket and augmented content fruition; and (iii) Inertial Navigation System (INS) and Global Navigation Satellite System (GNSS), in order to give them a feedback on their traversed path inside exhibition's location (through the INS) and outside around the city, visiting different exhibition places (by means of GNSS).

\subsection{Energy}

The environmental impact of cities, which nowadays consume $75 \%$ of natural resources and produce $60 \% \div 80 \%$ of global greenhouse gas emissions, will grow as urbanization increases from $54 \%$ of the world population today to $66 \%$ by 2050 [79]. 
In the last years, in addition to traditional energy sources, many other terms have been associated with energy, including clean energy, green energy, sustainable energy, renewable energy, and smart energy. Therefore, the theme of energy, related to pollution and global warming, is now perceived by the people much more than in the past. In detail, clean energy (or green energy) suggests that the energy consumption has a very minimal negative impact on the environment, as shown in Figure 9.

Another related term is "zero-energy system" (or zero-energy buildings), in which the consumed energy balances the generated energy, with a net consumption to be considered as zero. Increasing resource efficiency at city scale would enable more sustainable solutions and help to transition to carbon-free economy while meeting the challenges of increasing population in such areas. This also leads to the concept of Positive Energy Districts (PEDs), corresponding to city areas where the energy balance (produced-consumed) is positive. The vision for future smart energy systems is to have algorithms which can learn user demand and usage profiles from historical data [80], thus leveraging this information to optimize, coordinate, and control the distribution of different energy vectors. As embedded algorithms become more pervasive at different levels of the energy network, Artificial Intelligence (AI), including ML as a special class, would become increasingly important for the smart cities of the future.

Finally, smart energy is much broader than any of the previous concepts, as it can be seen as related to an "Internet of Energy" model [81]. In detail, a smart energy system consists of the intelligent integration of decentralized sustainable energy sources, efficient distribution, and optimized power consumption. The core of a smart energy system is the information infrastructure, which is responsible for collecting the energy consumption information and sharing the provider rate information. In this case, IoT-oriented solutions can be used to control the operations with an appropriate level of energy consumption for smart appliances like dishwashers and water heaters. Another relevant aspect for smart cities of the future is the rapid diffusion of electric cars and plug-in station for charging electric vehicles; even in this case, IoT can support this carbon-to-electricity transition by providing both vehicles and recharging stations with mechanisms for contactless data exchange and billing, as well as improving data interconnection, exchange, and analysis through Vehicle-to-Vehicle (V2V) paradigms. Optimized system energy consumption is another key point of a smart energy system: the effective use of efficient energy storage, smart metering, and effective energy management can be keys for optimizing energy consumption in a smart city, possibly aided and enhanced by IoT-oriented solutions, as discussed before.

\subsection{Water and Air Quality}

Water and air quality in a city are strictly related to energy management applied methods, as it is well known that saving energy mechanisms and producing from renewable sources have also a strong impact on the quality of air (both outdoor [82] and indoor [83]) and on water pollution. This is a critical issue that cannot be ignored, as it is well-known that the air pollution has a significant risk factor for human health. Transportation, road traffic, home heating, industrial emissions, and other antropic activities are the major emission sources of toxic gases (e.g., $\mathrm{NO}_{x}, \mathrm{O}_{3}$, and $\mathrm{CO}$ ), volatile organic compounds (benzene, toluene, and xylene), greenhouse gases $\left(\mathrm{CO}_{2}, \mathrm{CH}_{4}\right.$, and $\left.\mathrm{N}_{2} \mathrm{O}\right)$, and particulate matter $\left(\mathrm{PM}_{10}, \mathrm{PM}_{5.0}, \mathrm{PM}_{2.5}\right.$, and $\left.\mathrm{PM}_{1.0}\right)$.

Air pollution not only has negative effects on public health, but also on the environment, as acid rains, smog, ozone layer reduction, and global warming damage the environment in multiple ways. Air pollution and air quality monitoring, through the introduction of IoT technologies, are strictly necessary in a smart sustainable city to implement reduction strategies and stimulate environmental awareness in people's community [84]. Several techniques and technologies can be used to monitor air quality, as shown in Figure 9. Currently, traditional environmental monitoring methods, such as air quality monitoring stations, are precise but expensive and bulky. These high-cost and high-accuracy air quality monitoring stations, based on chemical analyzers, are used to address the environmental 
regulations and standards. Generally, they are less densely employed and provide sensing data at low-spatial resolution in the cities.

Therefore, air quality monitoring systems based on low-cost and accurate sensors to be integrated in WSNs distributed at high-spatial resolution in the smart cities can be a valid and effective tool for real-time ubiquitous monitoring, in order to support decisions and to keep the general public informed on city status [85]. For example, in the city of Uppsala (Finland), with the GreenIoT project, a vehicular network of sensing nodes has been implemented [86]. Following this distributed approach, the collected data can help to measure the daily individual exposure to air pollutant by combining context-aware information, given by users' smartphones, and urban air pollution levels provided by the sensing layer [87].

Water management is a critical aspect to ensure sustainability, as water scarcity and water stress issues have become clear threats to the global population, as shown in Figure 10. Water is one of the most crucial elements for human life, as it is used for drinking, domestic use, and food production. To this end, it is imperative for municipalities to maintain a good water quality balance; otherwise, it would severely damage the health of the humans and, at the same time, affect the rest of the natural environment. Water pollution is the major global problem which thus requires a fast intervention water resource management in different levels: from international down to individual entities. It has been verified that water pollution is the leading cause of mortality and diseases worldwide [88]. A distributed sensing approach — similar to the one adopted for air quality monitoring-has been extended in the last years also to water monitoring [89]. Traditional methods are based on manual and laboratory-based analyses, in which water samples are analyzed in specific laboratories, with some drawbacks, such as the need of expensive devices, trained personnel, and the absence of real-time monitoring (the sample has to be brought to the laboratory). With the advent of IoT-based solutions, the distributed sensing is appealing also for the smart cities of the future. Even in the case of water and air quality monitoring, a municipality can evaluate the adoption of IoT-oriented solutions to be deployed on both private and public sites. This can provide several benefits on both technical and economic sides, thanks to the miniaturization of IoT sensing nodes and their ability to communicate in a wireless way, thus exploiting possibly available public wireless networks (e.g., spread directly by the municipality itself), as well as to the cost reduction by a high amount of deployed devices. To this end, the economic benefit can thus reach private citizens, who, in turn, will pay less for these municipality-provided services.

\subsection{Legality and Security}

As already mentioned for other aspects, although cities are trying to become smarter by adopting different solutions, smart city applications highlight a series of challenges and concerns in terms of privacy and security, as city operators should be able to defend the generated or collected information (regarding all the entities involved in the life of the city itself) from unauthorized access, modification, inspection, disclosure, and disruption [4]. Therefore, as shown in Figure 7, privacy and security requirements underlying the overall infrastructure, which the city lives on, including availability, integrity, confidentiality, access control, and non-repudiation, should be handled and satisfied [90].

As widely known, securing a smart city is not easy and faces a set of challenges which should be carefully considered. On one hand, a smart city collects (from IoT-oriented on-field sensing nodes) privacy-sensitive and granular-scale data regarding the environment and people's lives, while, on the other hand, produces estimations and takes decisions based on these information, which, in a certain way, impacts people's lives. This is why privacy and security issues become challenging and should be carefully considered, especially in the light of modern IoT-oriented processing mechanisms, and enhanced and distributed Fog/Edge/Cloud Computing-based data analysis infrastructures.

Looking in detail at these issue, a first vulnerability is related to privacy leakage and data inferring by external attackers, operated when private data (e.g., regarding citizen's identity and location in a certain time instant, health condition, biometrical information inferred from intelligent surveillance) 
are collected, transmitted, and processed. As a solution, off-the-shelf privacy and security techniques can be applied [91,92], as in the case of surveillance systems capturing user-related information (e.g., a security camera, used to detect abnormal events or theft) [92-94].

A second vulnerability is related to the fact that, as a city (and, of course, a smart city) has a two-way control flow-sensors, to sense physical quantities, and actuators, to act on the environment on the basis of the processed data, this flow should be protected against attacks of heterogeneous nature. Illustrative attacks are malicious data injection, spoofing attacks, Denial of service (DoS) attacks, and Distributed DoS (DDoS) attacks. Moreover, operators should care about third-party components and plug-ins, as these are often the preferred targets of the attackers [95].

With regard to intelligent healthcare, especially with reference to the COVID-19 pandemic experienced all around the world in 2020, a smart city could rely on the technology to counteract the diffusion of the virus with innovative solutions. If an old-fashioned prevention approach suggests to isolate susceptible people for a certain period, but not considering the possible negative impacts, such as panic or anxiety among the society, economic loss of the isolated people, and massive healthcare expense, then the fusion of data gathered from heterogeneous sources (e.g., social networks, real-time health monitoring systems, etc.) would allow to obtain better results [96,97]. In this context, IoT could support the implementation of an "Internet of People" platform.

Another example could be related to the energy management in citizens' houses. In this case, a smart city may target an intelligent energy billing and invoicing through the deployment of a smart grid infrastructure, composed of a multitude of domestic smart meters. Although this may provide several benefits, as highlighted in Section 3.7, various attacks can be attempted to perform malicious actions, such a tampering with smart meter records, forwarding altered data to the grid's control center, and introducing intrusive and unauthorized smart meters, trying to steal sensitive data. In order to counteract these threats, cryptographic algorithms, privacy-preserving aggregation schemes [98], or adaptive key management schemes can be adopted to avoid disclosure to untrusted entities [99].

Finally, legality in smart cities will thus involve the definition of distributed security plans involving security cameras and similar modules spread around the city. In addition to these cameras, municipality owners may use IoT-oriented security devices that are both fixed (in proper locations) and mobile (e.g., carried by police officers, etc.).

\subsection{Green Urban Areas}

Within the smart city, another important aspect to be considered is the management of the green areas of the city itself. Motivated by the ecological movement and given the very high sensitivity of citizens towards the environmental theme, the management of green areas is of fundamental importance from a strategic point of view, as shown in Figure 9. The creation of management systems based on the IoT generates many advantages in energetic and economical terms. For example, a first tangible direct result obtained is the saving of water resources, as intelligent systems decide the quantities of water which are sufficient to irrigate the soil, taking into account soil humidity conditions, and weather conditions. Water used in urban irrigation, in fact, reaches $56 \%$ of water usage in cities [100].

A second optimization element refers to time and travel savings, including the reduction of on-site activities by technicians who can remotely identify leaks or system breakdowns, based on the expected irrigation and the values of the sensors and actuators, and, therefore, only intervene on site if necessary. This, evidently, brings significant benefits towards the environment, in terms of water savings, economic savings, and reduction of unnecessary movements (which, in turn, also has a positive impact on air pollution). Finally, the quality of life of the citizens themselves improves, as they can benefit from well looked after care green areas and, therefore, from a cleaner and healthier environment. Even in the case of green areas management, the IoT can be a good aiding paradigm for municipalities in this field, thanks to the availability of a wide plethora of small-sized IoT-oriented solutions allowing to remotely monitor the environmental situation and react efficiently depending on 
the environmental conditions, for example, to automate the irrigation based on heterogeneous data coming from the sensors spread inside the city limits; to interact with traffic controllers in order to deny the access to some particular areas, in case of air pollution parameters exceeding some thresholds (possibly calibrated through AI-based algorithms).

\section{Smart and Sustainable Urban Mobility}

As stated in Section 3.2, mobility is one of the pillars in the design of smart city services, and can significantly improve indicators for municipalities and stakeholders. In the following, a focus on smart mobility solutions and technologies is provided. It is well known that near-to-zero emissions and reduced traffic jams, in conjunction with the adoption of smart transportation approaches and IoT-oriented paradigms, will produce relevant impacts on the quality of life and the environment in smart cities, thus increasing virtuous habits among the citizens [101]. Therefore, the way mobility and transport aspects will be handled in smart cities is highly supported by the adoption of Intelligent Transportation Systems (ITSs), capable of managing traffic-related aspects (such as smart parking, car sharing [102], speed control systems, etc.), which will be fundamental in the future. To this end, the introduction of IoT-related concepts in conjunction with ITSs will certainly impact mobility and transport applications $[103,104]$. This trend will dramatically change the way city operators and people living the city itself will interact with its nearby infrastructure: how citizens live and move in the city (e.g., roads, streets, cycle paths, public transport stations, private and public parking spaces, etc.), how the city entities (e.g., mobility operators and transport units) plan their activities and configure the transportation infrastructure-through the concept of Vehicular Area Networks (VANETs) [105,106]—and how these planning activities are managed and performed [107].

This further highlights the fact that several trends are changing the landscape of modern cities, as life becomes more connected and augmented by the technology, modern urban economies require a fast Internet connectivity (and scalable IoT-based solutions), and citizens need fast, accessible, and on-demand forms of transportation [108].

In general, a complete infrastructure willing to integrate the sustainable mobility concept with IoT-oriented paradigms, has to be able to perform several tasks, as shown in Figure 11, with particular focus on the data resulting from these mobility-related scenarios, as follows.

- Support both local and isolated scenarios (not connected to the Internet), and fully on-Cloud architectures, in order to continuously collect a large amount of heterogeneous data from the city infrastructure [109], supporting several paradigms for data injection (e.g., on-demand data, proactive forward, scheduled forward, etc.) [110,111].

- Handle safety-critical scenarios, where involved entities (both IoT-related and not) should interact with the municipality's control centers (e.g., traffic congestion area, pedestrian crossing paths, event mass moving) in a safe and secure way, even providing mechanisms to cope with the lack of connection/communication [112].

- Guarantee proper data management, according to data protections regulations [113] (e.g., the General Data Protection Regulation, GDPR [114]) and with respect of their ownership and protecting the involved entities [115] —as discussed in Section 3.9-against possible data threats (e.g., external intrusions, data tampering, Man-in-the-Middle (MITM) attacks, data sniffing, etc.), informing law enforcement agencies in case of data breaches [91,116];

- Provide distributed storage mechanisms, in order to decentralize the mobility network (and avoid bottlenecks often affecting centralized solutions), thus supporting efficient strategies for data retrieval and disaster recovery.

- Provide high-layer mechanisms for the execution of AI and other data analysis algorithms, in order to extract features and implement predictive mechanisms based on the collected environmental data (e.g., smart parking, predictions on traffic flow, and traffic flow reconstruction) $[117,118]$. 
- Provide several easy-to-use visual consultation mechanisms for mobility data, through various representation technologies, based on the roles of the different users accessing them [119].

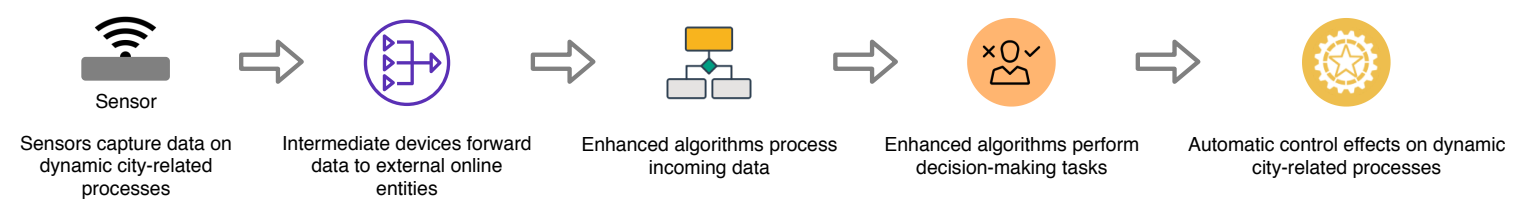

Figure 11. Data traffic's pipeline from the field to the processing arena.

Considering the communication between IoT devices-deployed within city limits and monitoring the different aspects of the citizens' life-and the infrastructure in which the data processing is performed, it can be useful to introduce a particular class of IoT nodes, denoted as IoT Hubs or IoT GWs, characterized by enhanced capabilities of local computing. In turn, these IoT Hubs should be further enhanced with on-Edge capabilities, in order to provide innovative ways to handle a sustainable mobility as expected in modern smart cities. Furthermore, IoT GWs have to cope with the following different aspects, on both local and remote sides:

- Inform drivers and people on the street with dynamic signals (directly on the road) based on the environmental conditions sensed by local sensors; examples of these signals are speed limits, presence of speed meters, indications on traffic condition, and planning for public transportation [120].

- Collect traffic flow information through sensors deployed on the road, thus estimating some key features characterizing the mobility conditions: amount of cars passing a specific segment and density of trucks, cars, and motorcycles [121].

- Counting people's density and flows moving in particular areas, through the usage of heterogeneous sensing nodes, based on heterogeneous sensors (such as optical and proximity sensors), and using IEEE 802.11 or BLE communication protocols [122]. As an example, these sensing elements could be placed in bus/train stations, cultural (e.g., museums) and crucial and strategic areas (e.g., train stations and airports).

In order to avoid resource-constrained IoT nodes from heavy processing tasks, yet benefiting from the possibility to extract overall features based on the data arriving from each local sector of the city, some processing activities can be delegated to Edge and Cloud infrastructures. Illustrative examples of these activities are the following.

- Prediction of free parking slots, delay of buses at bus stops, bikes to be shared from a given point, traffic flow at some points.

- Data visualization for mobility and transport control room operators, to transmit alarms in the case of early warning conditions and to monitor the current global traffic situation [123], in order to predict road traffic congestion and suggest alternative ways to reach a Point of Interest (POI) [124].

- ML-aided algorithms execution on traffic data, in order to suggest alternative paths for people in certain conditions, e.g., to avoid queues in congested areas and to promote new and alternative tours.

- AI-based algorithm execution for user behavior and engagement classification, in order to better understand how citizens use the city infrastructure and propose changes to promote virtuous behaviors [125].

Considering the green evolution in the sustainable mobility of a smart city (as briefly discussed in Section 3.10), it is interesting to analyze how it is possible to improve the quality of life of citizens when they deal with different types of vehicles (e.g., public buses, vans, private cars, motorcycles, bicycles, and scooters) [126], as shown in Figure 12. 


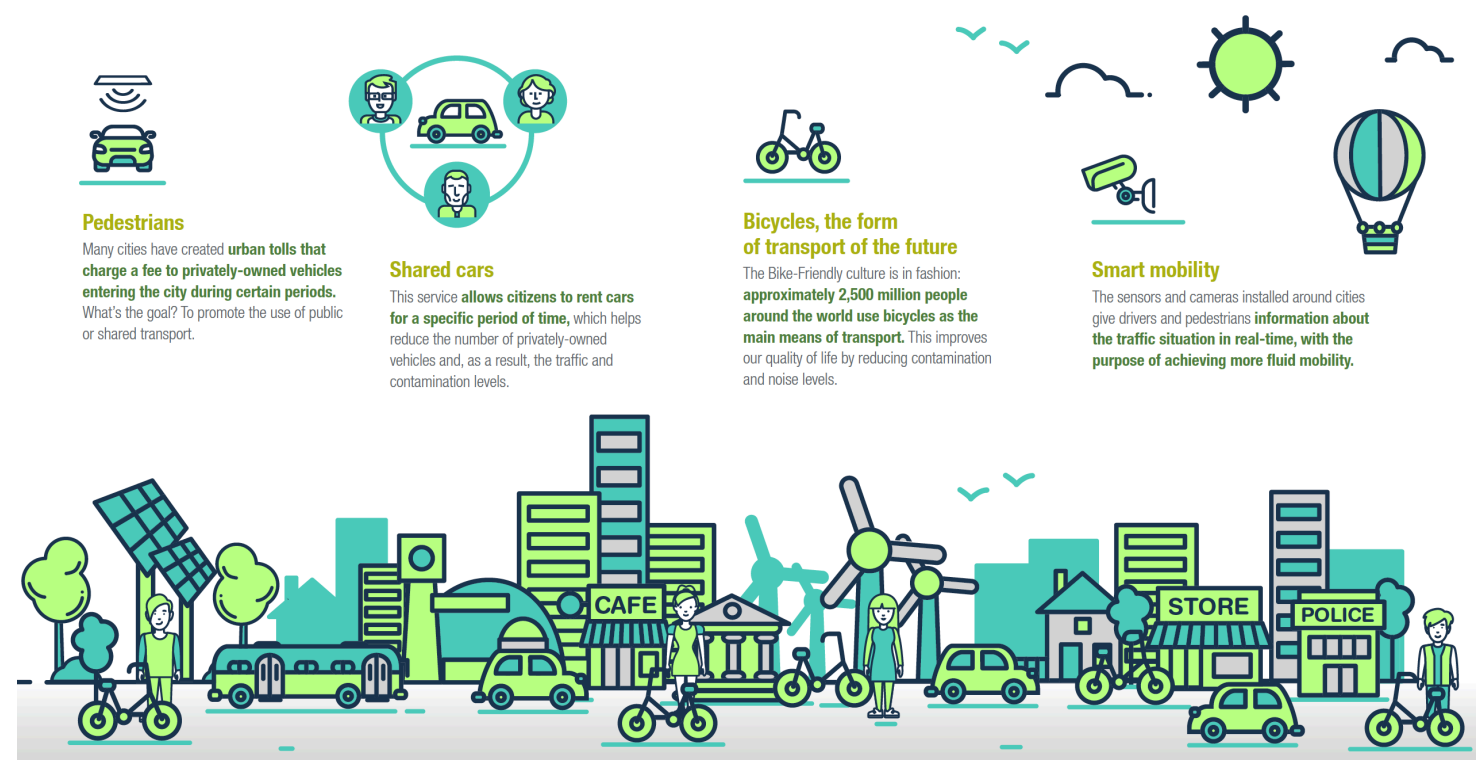

Figure 12. Mobility models applicable in a smart city [127].

Thanks to this need for a better life quality of people living in a city, it is possible to conclude that a smart sustainable urban mobility model will need to follow the following principles $[128,129]$.

- Flexibility: multiple modes of transportation allow travelers to choose which ones work best for a given situation.

- Efficiency: the trip gets the travelers to their destination with minimal disruption and in as little time as possible [130].

- Integration: the full route is planned door-to-door, regardless of which modes of transportation are used.

- Clean Technology: transportation moves away from pollution-causing vehicles to zeroemission ones.

- Safety: fatalities and injuries are drastically reduced.

A smart city will be equipped with a monitoring system composed by a heterogeneous capillary sensor network [131] for targeting the reduction of the traffic within city limits, in which one of the first goal is to block vehicles in entering some zones of the city, in case of needs or based on permissions released to drivers (e.g., inside Limited Traffic Zone). This can be made by spreading sensors around the city and closing the entrance in case pollution exceeds properly set thresholds. Therefore, the definition of these policies and their corresponding data processing can be delegated on-Edge (building a sort of "network-of-networks" monitoring a sector of the municipality and, thus, relieving each single sensing node from this processing task) as well as on-Cloud ("logically" centralizing the decision process). In both cases, AI-based algorithms can be embedded in powerful processing nodes, as well as exploiting the potentialities of cooperative processing-shared among the involved nodes, while a logically-centralized rules definition allows to implement a plan based on the smart city's overall situation awareness.

Another infrastructure which can improve the smartness of a city is associated with the deployment of several sensors to survey acoustic pollution and people flows inside the city limits. Both these monitoring systems can be spread in the smart city as a sensory network useful to retrieve information on noise levels in certain critical areas of the city itself, such as areas with high attendance in certain hours (e.g., pub areas frequented by young people) and along one of the main routes for city traffic. In fact, these systems allow to identify which are the most critical moments, giving this essential information to the municipality for planning future interventions in terms of organizing events. 
Another hot topic on which a smart city may demonstrate to target a sustainable mobility is on boosting the utilization of electrical vehicles inside its city limits: this holds for both public and private transportation, as discussed in Section 3.7. With regard to the public case, the replacement of the public transport's vehicle fleet with electric vehicles is encouraged, thus reducing pollution emissions [132] (e.g., as detailed in Section 3.8, particulate matter, $\mathrm{PM}_{10}, \mathrm{PM}_{2.5}, \mathrm{NO}_{x}, \mathrm{O}_{3}, \mathrm{CO}, \mathrm{CO}_{2}, \mathrm{CH}_{4}$, and $\mathrm{N}_{2} \mathrm{O}$ ) and reducing oil-powered vehicles, thus providing citizens several benefits (e.g., ticket price's reduction). Instead, with reference to private transportation, the provision of recharging stations for electrical vehicles improve the citizen's awareness in buying electrical vehicles, especially for those whose habitual travels are inside the city limits. Moreover, this allows to build an integrated network of recharging stations on top of which the municipality can define new services, such as an overall infrastructure for paying the electricity refill, obtaining at the same time a reward based on the usage of electrical vehicles (e.g., to be discounted from the taxes to be payed by the citizen).

An additional valuable deployment for supporting the aforementioned topics regards the smart monitoring of parking slots for different types of vehicles [133]. This can take place through a network of heterogeneous sensors, partly embedded in the asphalt and partly through the utilization of optical devices, while data processing can be performed, as for previously mentioned scenarios, both locally and remotely. In the first case, it can be required to send only few aggregated data: this can require the adoption of low-power and low data rate transmission protocols (e.g., LoRa), in order to reach edge nodes without the need of cellular (e.g., LTE-4G/5G) or IEEE 802.11 connectivity. In the latter case, high-level ML-based processing can be performed and, on the basis of the obtained results, the municipality can make decisions, such as improving the number of public scooters available in specific city areas, better organizing the availability of parking for the disabled, and applying a rotating usage of the loading/unloading parking slots differentiated per daily hour.

As a final remark, in order to further integrate all the aforementioned scenarios and aspects useful for representing how a city may aim at becoming a smart city, the value and reliability of the large amount of data produced in each scenario-often represented by high stream of data [134], in case of video-based services_can be enriched by the adoption of a municipality-owned blockchain mechanism [135-137]: this paves the way to several additional services to be provided to citizens that involve different aspects of their daily life.

\section{Future Research Directions}

The objectives detailed in Section 2 and the indicators discussed in Section 3 (on the basis of which a smart city may evolve) can be taken as guidelines by cities worldwide in order to scale up and improve their value for the different actors interacting with them [138]. As highlighted also in Section 4 , this is even supported by a strong communication and rational decision making, together with the promotion of private-public partnership projects, and efficient and focused synergies between old cities and new cities, along with differentiated city models, as proposed for the Korean city of Gyeonggi-do [139]. With regard to these city models, the following city categories, valid for cities all over the world, can be defined; (i) efficient city management, (ii) regional regeneration, (iii) low-carbon eco-friendly, and (iv) industry development-oriented [140].

Concerning the efficient city management category, London and Glasgow, England, plan to introduce a smart system to provide citizens with better city infrastructures for environment and job [141,142], thus expanding city services required by businesses. The final aim is to increase the efficiency of urban management, in order to foster technology innovation industry, and to secure the quality of life. In a similar way, the Smart America project [143] in the US has been implemented with the goal of applying Cyber-Physical Systems (CPSs) to the real world, in order to enable different technologies (e.g., home/building, climate/environment, disaster recovery, manufacturing, transportation, healthcare, security, and energy) in several daily contexts.

The regional regeneration category is representative of the innovation processes implemented in the European cities of Copenhagen, Denmark, and Barcelona, Spain. In detail, the Copenhagen 
municipality is promoting the cooperation between the government itself and the citizenship [144], aiming at developing an ecosystem in which private, business, public, and citizens cooperate and perform innovation activities in a given space or area (e.g., regarding the Danish port slum problem). Instead, the government of Barcelona is providing heterogeneous city-related data to citizens and public services [145], in order to easily access information, eco-friendly transportation infrastructure, and improve the residential environment of the urban space, thereby regenerating the urban space in an economical manner (e.g., regarding the municipal bike sharing service $[146,147])$.

With regard to the low-carbon eco-friendly category, different smart city-oriented projects will be applied in other two EU cities (namely, Nice, France, and Amsterdam, the Netherlands) and in Singapore [148]. The French city is designing an eco-city zone in the city center [149], in order to establish a municipal plan suitable to maintain environmentally-friendly cultural city, collecting various city data and providing the output of their consequent processing to citizens, aiming at improving citizen's convenience quality of life [150]. In a similar way, the Dutch city of Amsterdam, by combining technology and social infrastructures, is building a sustainable economic growth and safe society, thus aiming at reducing the annual amount of $\mathrm{CO}_{2}$ by using electric vehicles, smart building, smart grids, and smart meters [151,152].

Finally, the industry development-oriented category is illustrative of the initiatives taking place in Dubai, UAE, and in different cities in Japan. Dubai is planning to develop smart cities that can easily and quickly deliver information -including public services, education, health and security-through smart devices, to their citizens and tourists [153], while Japan has a long-term smart city development plan facilitating information collection [154-156].

Looking on "hot" future directions which may be followed in conjunction with smart cities, one can be referred to the definition and implementation of AI-oriented (e.g., Deep Learning, DL) methods for several aspects discussed in Sections 2 and 3. To this end, transfer learning regarding various aspects of a smart city, from one platform to another, as well as moving its related processing tasks, is a future direction, together with the integration of semantic technologies in high-layer applications, in order to enable better interaction of smart devices with the users living the city itself (e.g., workers, tourists, and citizens) [157]. Moreover, the use of virtual objects with AI algorithms would help in creating virtual representations of physical objects (i.e., digital twins) so that the objects can be modeled to be proactive and work automatically and autonomously [158].

Finally, as the usability of the smart devices play a significant role, and having that nowadays technologies and devices adopted in smart cities are often wearable [159] and mobile-allowing lesser technically savvy users to interact with the surrounding environment in a safe and secure way $[160,161]$ - the integration of technologies allowing Natural Language Processing (NLP) represents another potential future research direction.

\section{Conclusions}

In this paper, we have discussed and analyzed various aspects which modern cities are working on and targeting in order to enhance the management of resources and their services, with the ultimate goal to become smart sustainable cities. These heterogeneous activities can be measured through a set of indicators (specifically selected among potential ones), and trying to cover different aspects of urban life and of the people living in it, providing services and mechanisms with different purposes (e.g., more suitable for citizens, tourists, workers, institutions, etc.) through the introduction of IoT technologies. This is even more true in the light of the research directions that several cities around the globe, ranging from Parma, Italy, to Copenhagen, Denmark, and Japan and USA, are undertaking through the adoption of heterogeneous IoT-oriented solutions, with the aim of improving their offered services and crucial features which will represent the highway for the future of smart cities. With respect to the different initiatives undertaken by these municipalities, each city will surely benefit from these innovations and will be able to measure these benefits in both quantitative and qualitative ways, by benchmarking their innovation progresses against their current situation, as well as by means 
of feedback mechanisms directly from their citizens (e.g., satisfaction ratings through the official mobile App of each city, as well as exploiting Big Data and aggregating tourists' feedback attending restaurants and cultural locations). With the aim of providing a reference to researchers, companies, and institutions, we first described the possible options for the choice of smart city indicators and communication infrastructure technologies. Then, we presented a summary of the main smart city challenges, in order to give a comprehensive insight on possible fields of actions, with a particular attention to the smart mobility scenario. Finally, we remark that the discussed thematic areas cannot be considered as exhaustive, as the life of a city as a whole involves many interwoven aspects. Therefore, it is ever quite hard to be able to fully define all the viable ways in which city operators can enhance their city's services. However, without any doubt citizens will certainly benefit from the adoption of IoT-oriented solutions in the urban context in which they are immersed and which they contribute to improve with their actions.

Author Contributions: Conceptualization, L.B., A.C., L.D., G.F., P.A., F.D.N., A.D., C.P., M.M., and E.B.; methodology, L.B., A.C., L.D., and G.F.; software, L.B., A.C., and L.D.; validation, L.B., A.C., L.D., and G.F.; formal analysis, L.B., A.C., L.D., and G.F.; investigation, L.B., A.C., L.D., and G.F.; resources, L.B., A.C., and L.D.; data curation, L.B., A.C., L.D., and G.F.; writing - original draft preparation, L.B., A.C., and L.D.; writing-review and editing, L.B., A.C., L.D., and G.F.; visualization, L.B., A.C., L.D., G.F., P.A., F.D.N., A.D., C.P., M.M., and E.B.; supervision, G.F.; project administration, L.B., A.C., L.D., and G.F.; funding acquisition, L.B., A.C., L.D., G.F., P.A., F.D.N., A.D., C.P., M.M., and E.B. All authors have read and agreed to the published version of the manuscript.

Funding: This work is partially funded by the European Union's Horizon 2020 research and innovation program under Grant Agreement No. 731198, Ruggedised project-“"Rotterdam, Umea and Glasgow: Generating Exemplar Districts In Sustainable Energy Deployment." The work reflects only the authors' views; the European Commission is not responsible for any use that may be made of the information it contains. The work of L.D. is partially funded by the University of Parma, under "Iniziative di Sostegno alla Ricerca di Ateneo" program, "Multi-interface IoT sYstems for Multi-layer Information Processing" (MIoTYMIP) project.

Acknowledgments: The authors would like to express their sincere gratitude to Davide Alinovi for the work done when he was with the Internet of Things (IoT) Lab, and for his suggestions and collaboration.

Conflicts of Interest: The authors declare no conflict of interest. The funders had no role in the design of the study; in the collection, analyses, or interpretation of data; in the writing of the manuscript; or in the decision to publish the results.

\section{Abbreviations}

The following abbreviations are used in this manuscript.

$\begin{array}{ll}\text { AI } & \text { Artificial Intelligence } \\ \text { AR } & \text { Augmented Reality } \\ \text { BLE } & \text { Bluetooth Low Energy } \\ \text { DDoS } & \text { Distributed DoS } \\ \text { DL } & \text { Deep Learning } \\ \text { DoS } & \text { Denial of Service } \\ \text { GDPR } & \text { General Data Protection Regulation } \\ \text { GIS } & \text { Geographic Information System } \\ \text { GNSS } & \text { Global Navigation Satellite System } \\ \text { GPS } & \text { Global Positioning System } \\ \text { GW } & \text { Gateway } \\ \text { H2H } & \text { Human-to-Human } \\ \text { KPI } & \text { Key Performance Indicator } \\ \text { ICT } & \text { Information Communication Technologies } \\ \text { INS } & \text { Inertial Navigation System } \\ \text { IoT } & \text { Internet of Things } \\ \text { ITS } & \text { Intelligent Transportation System } \\ \text { LPWAN } & \text { Low-Power Wide-Area Network } \\ \text { M2M } & \text { Machine-to-Machine } \\ \text { MITM } & \text { Man-in-the-Middle } \\ \text { ML } & \text { Machine Learning }\end{array}$




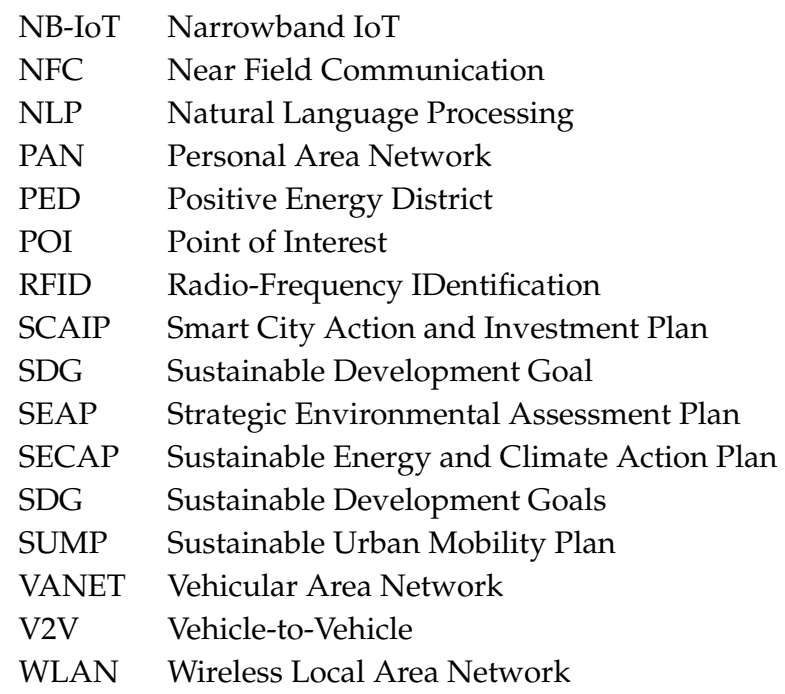

\section{References}

1. Dameri, R.P. Searching for smart city definition: A comprehensive proposal. Int. J. Comput. Technol. 2013, 11, 2544-2551. [CrossRef]

2. Imperatives, S. Report of the World Commission on Environment and Development: Our Common Future. 1987, Volume 10. Available online: http:/ / www.ask-force.org/web/Sustainability/BrundtlandOur-Common-Future-1987-2008.pdf (accessed on 10 July 2020).

3. Kennedy, C.; Cuddihy, J.; Engel-Yan, J. The changing metabolism of cities. J. Ind. Ecol. 2007, 11, 43-59. [CrossRef]

4. Zhang, K.; Ni, J.; Yang, K.; Liang, X.; Ren, J.; Shen, X.S. Security and Privacy in Smart City Applications: Challenges and Solutions. IEEE Commun. Mag. 2017, 55, 122-129. [CrossRef]

5. Bibri, S.E.; Krogstie, J. Smart sustainable cities of the future: An extensive interdisciplinary literature review. Sustain. Cities Soc. 2017, 31, 183-212. [CrossRef]

6. Ruggedised European Project. Available online: https://ruggedised.eu/ (accessed on 10 July 2020).

7. IoT Analytics. LPWAN Emerging as Fastest Growing IoT Communication Technology. Available online: https: / iot-analytics.com/lpwan-market-report-2018-2023-new-report/ (accessed on 25 August 2020).

8. Cilfone, A.; Davoli, L.; Belli, L.; Ferrari, G. Wireless Mesh Networking: An IoT-Oriented Perspective Survey on Relevant Technologies. Future Internet 2019, 11, 99. [CrossRef]

9. Davoli, L.; Belli, L.; Cilfone, A.; Ferrari, G. From Micro to Macro IoT: Challenges and Solutions in the Integration of IEEE 802.15.4/802.11 and Sub-GHz Technologies. IEEE Internet Things J. 2018, 5, 784-793. [CrossRef]

10. LPWAN Technologies: A Game Changer for Smart Cities. Available online: https:/ / www.maravedis-bwa. com/2017/09/18/lpwan-technologies-a-game-changer-for-smart-cities/ (accessed on 25 August 2020).

11. Gozalvez, J. New 3GPP standard for IoT [mobile radio]. IEEE Veh. Technol. Mag. 2016, 11, 14-20. [CrossRef]

12. Feltrin, L.; Tsoukaneri, G.; Condoluci, M.; Buratti, C.; Mahmoodi, T.; Dohler, M.; Verdone, R. Narrowband IoT: A survey on downlink and uplink perspectives. IEEE Wirel. Commun. 2019, 26, 78-86. [CrossRef]

13. Magrin, D.; Centenaro, M.; Vangelista, L. Performance evaluation of LoRa networks in a smart city scenario. In Proceedings of the 2017 IEEE International Conference on Communications (ICC), Paris, France, 21-25 May 2017; pp. 1-7.

14. Rao, S.K.; Prasad, R. Impact of 5G technologies on smart city implementation. Wirel. Pers. Commun. 2018, 100, 161-176. [CrossRef]

15. Yaqoob, I.; Hashem, I.A.T.; Mehmood, Y.; Gani, A.; Mokhtar, S.; Guizani, S. Enabling communication technologies for smart cities. IEEE Commun. Mag. 2017, 55, 112-120. [CrossRef]

16. Sustainable Cities and Communities_Indicators for City Services and Quality of Life, 2nd ed.; 2018. Available online: https:/ / www.iso.org/standard/68498.html (accessed on 25 August 2020).

17. Indicators for Sustainable Cities. Available online: https://ec.europa.eu/environment/integration/ research/newsalert/pdf/indicators_for_sustainable_cities_IR12_en.pdf (accessed on 10 July 2020). 
18. Smart City Indicators. Available online: https://hub.beesmart.city/en/smart-city-indicators (accessed on 25 August 2020).

19. Huovila, A.; Bosch, P.; Airaksinen, M. Comparative analysis of standardized indicators for Smart sustainable cities: What indicators and standards to use and when? Cities 2019, 89, 141-153. [CrossRef]

20. Monzon, A. Smart Cities Concept and Challenges: Bases for the Assessment of Smart City Projects. In Proceedings of the 2015 International Conference on Smart Cities and Green ICT Systems (SMARTGREENS), Lisbon, Portugal, 20-22 May 2015; pp. 1-11.

21. Faria, R.; Brito, L.; Baras, K.; Silva, J. Smart Mobility: A Survey. In Proceedings of the 2017 International Conference on Internet of Things for the Global Community (IoTGC), Funchal, Portugal, 10-13 July 2017; pp. 1-8.

22. Farooqi, N.; Gutub, A.; Khozium, M.O. Smart community challenges: Enabling IoT/M2M technology case study. Life Sci. J. 2019, 16, 11-17.

23. iCityRank 2019. Available online: https://d110erj175o600.cloudfront.net/wp-content/uploads/2019/11/ICity-Rank-2019.pdf (accessed on 10 July 2020).

24. Parma Futuro Smart. Available online: http://parmafuturosmart.comune.parma.it/ (accessed on 3 August 2020).

25. Satellite Applicatications Enhancing Quality of Life in Cities. Available online: https://www.eurisy.org/ event-Space4Cities/WhySatellites (accessed on 25 August 2020).

26. Badii, C.; Bellini, P.; Difino, A.; Nesi, P. Sii-Mobility: An IoT/IoE Architecture to Enhance Smart City Mobility and Transportation Services. Sensors 2019, 19, 1. [CrossRef] [PubMed]

27. Qiu, R.G.; Zu, T.; Qian, Y.; Qiu, L.; Badr, Y. Leveraging Big Data Platform Technologies and Analytics to Enhance Smart City Mobility Services. In Handbook of Service Science, Volume II; Springer International Publishing: Cham, Switzerland, 2019; pp. 567-587.

28. Bacic, Z.; Jogun, T.; Majic, I. Integrated Sensor Systems for Smart Cities. Teh. Vjesn. 2018, 25, $277-284$.

29. Suciu, G.; Butca, C.; Dobre, C.; Popescu, C. Smart City Mobility Simulation and Monitoring Platform. In Proceedings of the 2017 21st International Conference on Control Systems and Computer Science (CSCS), Bucharest, Romania, 29-31 May 2017; pp. 685-689.

30. Fu, S. Smart Café Cities: Testing human capital externalities in the Boston metropolitan area. J. Urban Econ. 2007, 61, 86-111. [CrossRef]

31. Lucas, R.E. On the Mechanics of Economic Development. J. Monet. Econ. 1988, 22, 3-42. [CrossRef]

32. Romer, P.M. Increasing Returns and Long-Run Growth. J. Political Econ. 1986, 94, 1002-1037. [CrossRef]

33. Henderson, J.V. The Sizes and Types of Cities. Am. Econ. Rev. 1974, 64, 640-656.

34. Fujita, M.; Ogawa, H. Multiple equilibria and structural transition of non-monocentric urban configurations. Reg. Sci. Urban Econ. 1982, 12, 161-196. [CrossRef]

35. Marshall, A. Principles of Economics; Cosimo, Inc.: New York, NY, USA, 2009.

36. Palivos, T.; Wang, P. Spatial agglomeration and endogenous growth. Reg. Sci. Urban Econ. 1996, 26, 645-669. [CrossRef]

37. Eaton, J.; Eckstein, Z. Cities and growth: Theory and evidence from France and Japan. Reg. Sci. Urban Econ. 1997, 27, 443-474. [CrossRef]

38. Black, D.; Henderson, V. A Theory of Urban Growth. J. Political Econ. 1999, 107, 252-284. [CrossRef]

39. Shapiro, J.M. Smart Cities: Quality of Life, Productivity, and the Growth Effects of Human Capital. Rev. Econ. Stat. 2006, 88, 324-335. [CrossRef]

40. Smart City Implementation Vision. Available online: https://www.transportation.gov/smartcity/winner (accessed on 25 August 2020).

41. Andersen, C.U.; Pold, S.B. Occupation of the "Open City". In MAB' 12: Proceedings of the 4th Media Architecture Biennale Conference: Participation; Association for Computing Machinery: New York, NY, USA, 2012; pp. 1-4.

42. Bayer, P.; Ross, S.L.; Topa, G. Place of Work and Place of Residence: Informal Hiring Networks and Labor Market Outcomes. J. Political Econ. 2008, 116, 1150-1196. [CrossRef]

43. Marchiori, M. The Smart Cheap City: Efficient Waste Management on a Budget. In Proceedings of the 2017 IEEE 19th International Conference on High Performance Computing and Communications, Bangkok, Thailand, 18-20 December 2017; pp. 192-199. 
44. Anagnostopoulos, T.; Zaslavsky, A.; Kolomvatsos, K.; Medvedev, A.; Amirian, P.; Morley, J.; Hadjieftymiades, S. Challenges and Opportunities of Waste Management in IoT-Enabled Smart Cities: A Survey. IEEE Trans. Sustain. Comput. 2017, 2, 275-289. [CrossRef]

45. Abdullah, N.; Alwesabi, O.A.; Abdullah, R. IoT-Based Smart Waste Management System in a Smart City. In Recent Trends in Data Science and Soft Computing; Saeed, F., Gazem, N., Mohammed, F., Busalim, A., Eds.; Springer International Publishing: Cham, Switzerland, 2019; pp. 364-371.

46. Nandico, O.F. A Framework to Support Digital Transformation. In Emerging Trends in the Evolution of Service-Oriented and Enterprise Architectures; Springer International Publishing: Cham, Switzerland, 2016; pp. 113-138.

47. Gartner Top 10 Strategic Technology Trends for 2019. Available online: https://www.gartner.com/ smarterwithgartner/gartner-top-10-strategic-technology-trends-for-2019/ (accessed on 26 July 2020).

48. Hämäläinen, M. A Framework for a Smart City Design: Digital Transformation in the Helsinki Smart City. In Entrepreneurship and the Community: A Multidisciplinary Perspective on Creativity, Social Challenges, and Business; Springer International Publishing: Cham, Switzerland, 2020; pp. 63-86.

49. Tomičić Pupek, K.; Pihir, I.; Tomičić Furjan, M. Smart City Initiatives in the Context of Digital TransformationScope, Services and Technologies. Management 2019, 24, 39-54.

50. Lederer, M.; Knapp, J.; Schott, P. The Digital Future Has Many Names-How business process management drives the digital transformation. In Proceedings of the 2017 6th International Conference on Industrial Technology and Management (ICITM), Cambridge, UK, 7-10 March 2017; pp. 22-26.

51. Crisostomi, E.; Shorten, R.; Wirth, F. Smart Cities: A Golden Age for Control Theory? IEEE Technol. Soc. Mag. 2016, 35, 23-24. [CrossRef]

52. Musa, S. Smart Cities-A Road Map for Development. IEEE Potentials 2018, 37, 19-23. [CrossRef]

53. Okrepilov, V.; Kuzmina, S.; Kuznetsov, S. Tools of quality economics: Sustainable development of a 'smart city' under conditions of digital transformation of the economy. IOP Conf. Ser. Mater. Sci. Eng. 2019, 497, 012134. [CrossRef]

54. Pappas, I.O.; Mikalef, P.; Giannakos, M.N.; Krogstie, J.; Lekakos, G. Big data and business analytics ecosystems: Paving the way towards digital transformation and sustainable societies. Inf. Syst. E Bus. Manag. 2018, 16, 479-491. [CrossRef]

55. Sarker, M.N.I.; Wu, M.; Hossin, M.A. Smart Governance through Bigdata: Digital Transformation of Public Agencies. In Proceedings of the 2018 International Conference on Artificial Intelligence and Big Data (ICAIBD), Chengdu, China, 26-28 May 2018; pp. 62-70.

56. Scriney, M.; Roantree, M. Efficient Cube Construction for Smart City Data. In Proceedings of the Workshops of the EDBT/ICDT 2016 Joint Conference, EDBT/ICDT Workshops 2016, Bordeaux, France, 15 March 2016; pp. 1-5.

57. Sharma, R.; Fantin, A.R.; Prabhu, N.; Guan, C.; Dattakumar, A. Digital literacy and knowledge societies: A grounded theory investigation of sustainable development. Telecommun. Policy 2016, 40, 628-643. [CrossRef]

58. Allam, Z.; Newman, P. Redefining the Smart City: Culture, Metabolism and Governance. Smart Cities 2018, 1, 4-25. [CrossRef]

59. Rom ao, J.; Kourtit, K.; Neuts, B.; Nijkamp, P. The smart city as a common place for tourists and residents: A structural analysis of the determinants of urban attractiveness. Cities 2018, 78, 67-75. [CrossRef]

60. Girard, L.; Nijkamp, P. Cultural Tourism and Sustainable Local Development; New Directions in Tourism Analysis; Taylor \& Francis: Abingdon, UK, 2016.

61. Angelidou, M.; Karachaliou, E.; Angelidou, T.; Stylianidis, E. Cultural Heritage in Smart City Environments. ISPRS Int. Arch. Photogramm. Remote Sens. Spat. Inf. Sci. 2017, 42, 27-32. [CrossRef]

62. Rom ao, J.; van Leeuwen, E.; Neuts, B.; Nijkamp, P. Tourist Loyalty and Urban E-Services: A Comparison of Behavioral Impacts in Leipzig and Amsterdam. J. Urban Technol. 2015, 22, 85-101. [CrossRef]

63. Rom ao, J.; Neuts, B.; Nijkamp, P.; van Leeuwen, E. Culture, Product Differentiation and Market Segmentation: A Structural Analysis of the Motivation and Satisfaction of Tourists in Amsterdam. Tour. Econ. 2015, 21, 455-474. [CrossRef]

64. La Rocca, R.A. The Role of Tourism in Planning the Smart City. TeMA J. Land Use Mobil. Environ. 2014, 7, 269-284. 
65. Garau, C. Emerging Technologies and Cultural Tourism: Opportunities for a Cultural Urban Tourism Research Agenda. In Tourism in the City: Towards an Integrative Agenda on Urban Tourism; Springer International Publishing: Cham, Switzerland, 2017; pp. 67-80.

66. Coccossis, H. Tourism and sustainability: Perspectives and implications. In Sustainable Tourism? European Experiences; CAB International: Wallingford, UK, 1996; pp. 1-21.

67. Butler, R. Alternative Tourism: The Thin Edge off the Wedge. In Tourism Alternatives; University of Pennsylvania Press: Philadelphia, PA, USA, 1992; pp. 31-46.

68. Coccossis, H.; Nijkamp, P. Sustainable Tourism Development; Ashgate Publishing: Farnham, UK, 1995.

69. Yiannakis, A.; Gibson, H. Roles Tourists Play. Ann. Tour. Res. 1992, 19, 287-303. [CrossRef]

70. Boes, K.; Buhalis, D.; Inversini, A. Smart tourism destinations: Ecosystems for tourism destination competitiveness. Int. J. Tour. Cities 2016, 2, 108-124. [CrossRef]

71. Sfandla, C.; Björk, P. Tourism Experience Network: Co-creation of Experiences in Interactive Processes. Int. J. Tour. Res. 2013, 15, 495-506. [CrossRef]

72. Sigala, M. WEB 2.0, Social Marketing Strategies and Distribution Channels for City Destinations: Enhancing the Participatory Role of Travelers and Exploiting their Collective Intelligence. In Web Technologies: Concepts, Methodologies, Tools, and Applications; IGI Global: Hershey, PA, USA, 2009; pp. 1249-1273.

73. Gil-Garcia, J.R.; Pardo, T.A.; Nam, T. What makes a city smart? Identifying core components and proposing an integrative and comprehensive conceptualization. Inf. Politys 2015, 20, 61-87. [CrossRef]

74. Mansson, M. Mediatized Tourism. Ann. Tour. Res. 2011, 38, 1634-1652. [CrossRef]

75. Colomb, C.; Novy, J. Protest and Resistance in the Tourist City; Routledge: New York, NY, USA, 2016.

76. Bimonte, S.; Punzo, L.F. Tourist Development and Host-Guest Interaction: An Economic Exchange Theory. Ann. Tour. Res. 2016, 58, 128-139. [CrossRef]

77. Wall, G.; Mathieson, A. Tourism: Change, Impacts, and Opportunities; Pearson Education: Upper Saddle River, NJ, USA, 2006.

78. Global Report on City Tourism. Available online: https://www.e-unwto.org/doi/abs/10.18111/ 9789284415300 (accessed on 25 July 2020).

79. World Urbanization Prospects 2018. Available online: https://population.un.org/wup/ (accessed on 10 July 2020).

80. Zhou, K.; Fu, C.; Yang, S. Big data driven smart energy management: From big data to big insights. Renew. Sustain. Energy Rev. 2016, 56, 215-225. [CrossRef]

81. Mohanty, S.P.; Choppali, U.; Kougianos, E. Everything you wanted to know about smart cities: The Internet of things is the backbone. IEEE Consum. Electron. Mag. 2016, 5, 60-70. [CrossRef]

82. Ambient (Outdoor) Air Pollution. Available online: https://www.who.int/news-room/fact-sheets/detail/ ambient-(outdoor)-air-quality-and-health (accessed on 10 July 2020).

83. Introduction to Indoor Air Quality. Available online: https://www.epa.gov/indoor-air-quality-iaq/ introduction-indoor-air-quality (accessed on 10 July 2020).

84. Ali, H.; Soe, J.K.; Weller, S.R. A real-time ambient air quality monitoring wireless sensor network for schools in smart cities. In Proceedings of the 2015 IEEE First International Smart Cities Conference (ISC2), Guadalajara, Mexico, 25-28 October 2015; pp. 1-6.

85. Moltchanov, S.; Levy, I.; Etzion, Y.; Lerner, U.; Broday, D.M.; Fishbain, B. On the feasibility of measuring urban air pollution by wireless distributed sensor networks. Sci. Total Environ. 2015, 502, 537-547. [CrossRef]

86. Kaivonen, S.; Ngai, E.C.H. Real-time air pollution monitoring with sensors on city bus. Digit. Commun. Netw. 2020, 6, 23-30. [CrossRef]

87. Lo Re, G.; Peri, D.; Vassallo, S.D. Urban Air Quality Monitoring Using Vehicular Sensor Networks. In Advances onto the Internet of Things: How Ontologies Make the Internet of Things Meaningful; Springer International Publishing: Cham, Switzerland, 2014; pp. 311-323.

88. Drinking Water Diseases and Contaminants. Available online: https://www.cdc.gov/healthywater/ drinking/public/water_diseases.html (accessed on 10 July 2020).

89. Perumal, T.; Sulaiman, M.N.; Leong, C.Y. Internet of Things (IoT) enabled Water Monitoring System. In Proceedings of the 2015 IEEE 4th Global Conference on Consumer Electronics (GCCE), Osaka, Japan, 27-30 October 2015; pp. 86-87.

90. Martinez-Balleste, A.; Perez-Martinez, P.A.; Solanas, A. The Pursuit of Citizens' Privacy: A Privacy-aware Smart City is Possible. IEEE Commun. Mag. 2013, 51, 136-141. [CrossRef] 
91. Elmaghraby, A.S.; Losavio, M.M. Cyber security challenges in Smart Cities: Safety, security and privacy. J. Adv. Res. 2014, 5, 491-497. [CrossRef]

92. Naphade, M.; Banavar, G.; Harrison, C.; Paraszczak, J.; Morris, R. Smarter Cities and Their Innovation Challenges. Computer 2011, 44, 32-39. [CrossRef]

93. Weber, R.H. Internet of Things-New security and privacy challenges. Comput. Law Secur. Rev. 2010, 26, 23-30. [CrossRef]

94. Gubbi, J.; Buyya, R.; Marusic, S.; Palaniswami, M. Internet of Things (IoT): A Vision, Architectural Elements, and Future Directions. Future Gener. Comput. Syst. 2013, 29, 1645-1660. [CrossRef]

95. Akhunzada, A.; Ahmed, E.; Gani, A.; Khan, M.K.; Imran, M.; Guizani, S. Securing Software Defined Networks: Taxonomy, Requirements, and Open Issues. IEEE Commun. Mag. 2015, 53, 36-44. [CrossRef]

96. Zhang, K.; Yang, K.; Liang, X.; Su, Z.; Shen, X.; Luo, H.H. Security and Privacy for Mobile Healthcare Networks: From a Quality of Protection Perspective. IEEE Wirel. Commun. 2015, 22, 104-112. [CrossRef]

97. Liu, J.; Li, Y.; Chen, M.; Dong, W.; Jin, D. Software-Defined Internet of Things for Smart Urban Sensing. IEEE Commun. Mag. 2015, 53, 55-63. [CrossRef]

98. Zhang, K.; Lu, R.; Liang, X.; Qiao, J.; Shen, X.S. PARK: A Privacy-preserving Aggregation Scheme with Adaptive Key Management for Smart Grid. In Proceedings of the 2013 IEEE/CIC International Conference on Communications in China (ICCC), Xi'an, China, 12-14 August 2013; pp. 236-241.

99. Li, X.; Lu, R.; Liang, X.; Shen, X.; Chen, J.; Lin, X. Smart Community: An Internet of Things Application. IEEE Commun. Mag. 2011, 49, 68-75. [CrossRef]

100. Domestic Water Use Study. Available online: https://www.water.wa.gov.au/_data/assets/pdf_file/0016/ 5029/42338.pdf (accessed on 10 July 2020).

101. Benevolo, C.; Dameri, R.P.; D'Auria, B. Smart Mobility in Smart City. In Empowering Organizations; Torre, T., Braccini, A.M., Spinelli, R., Eds.; Springer International Publishing: Cham, Switzerland, 2016; pp. 13-28.

102. Golbabaei, F.; Yigitcanlar, T.; Bunker, J. The Role of Shared Autonomous Vehicle Systems in Delivering Smart Urban Mobility: A Systematic Review of the Literature. Int. J. Sustain. Transp. 2020, 1-18. [CrossRef]

103. Mahrez, Z.; Sabir, E.; Badidi, E.; Saad, W.; Sadik, M. Smart Urban Mobility: When Mobility Systems Meet Smart Data. arXiv 2020, arXiv:2005.06626.

104. Gebresselassie, M.; Sanchez, T.W. "Smart" Tools for Socially Sustainable Transport: A Review of Mobility Apps. Urban Sci. 2018, 2, 45. [CrossRef]

105. Gorrieri, A.; Martalò, M.; Busanelli, S.; Ferrari, G. Clustering and sensing with decentralized detection in vehicular ad hoc networks. Ad Hoc Netw. 2016, 36, 450-464. [CrossRef]

106. Abdelgadir, M.; Saeed, R.A.; Babiker, A. Mobility Routing Model for Vehicular Ad-hoc Networks (VANETs), Smart City Scenarios. Veh. Commun. 2017, 9, 154-161. [CrossRef]

107. Su, K.; Li, J.; Fu, H. Smart city and the Applications. In Proceedings of the 2011 International Conference on Electronics, Communications and Control (ICECC), Ningbo, China, 9-11 September 2011; pp. 1028-1031.

108. Smart Urban Mobility: A Quick Start Guide. Available online: https://mobility.here.com/learn/smart-citymobility / smart-urban-mobility-quick-start-guide (accessed on 23 August 2020)

109. Tomaras, D. Crowdsourcing Techniques for Smart Urban Mobility. In Proceedings of the 2018 IEEE International Conference on Pervasive Computing and Communications Workshops (PerCom Workshops), Athens, Greece, 19-23 March 2018; pp. 460-461.

110. Sowe, S.K.; Kimata, T.; Dong, M.; Zettsu, K. Managing Heterogeneous Sensor Data on a Big Data Platform: IoT Services for Data-Intensive Science. In Proceedings of the 2014 IEEE 38th International Computer Software and Applications Conference Workshops, Vasteras, Sweden, 21-25 July 2014; pp. 295-300.

111. Fazio, M.; Paone, M.; Puliafito, A.; Villari, M. Heterogeneous Sensors Become Homogeneous Things in Smart Cities. In Proceedings of the 2012 Sixth International Conference on Innovative Mobile and Internet Services in Ubiquitous Computing, Palermo, Italy, 4-6 July 2012; pp. 775-780.

112. Rathore, M.M.; Ahmad, A.; Paul, A.; Rho, S. Urban planning and building smart cities based on the Internet of Things using Big Data analytics. Comput. Netw. 2016, 101, 63-80. [CrossRef]

113. Finck, M.; Lamping, M.; Moscon, V.; Richter, H. Smart Urban Mobility; Springer: Berlin/Heidelberg, Germany, 2020; Volume 29, p. 340. 
114. European Parliament and Council of the European Union. Regulation (EU) 2016/679 on the Protection of Natural Persons with Regard to the Processing of Personal Data and on the Free Movement of Such Data, and Repealing Directive (General Data Protection Regulation). Available online: https: / eur-lex.europa.eu/ legal-content/EN/TXT/HTML/?uri=CELEX:32016R0679 (accessed on 22 July 2020).

115. Lenz, B.; Heinrichs, D. What Can We Learn from Smart Urban Mobility Technologies? IEEE Pervasive Comput. 2017, 16, 84-86. [CrossRef]

116. Belli, L.; Cirani, S.; Davoli, L.; Ferrari, G.; Melegari, L.; Picone, M. Applying Security to a Big Stream Cloud Architecture for the Internet of Things. Int. J. Distrib. Syst. Technol. (IJDST) 2016, 7, 37-58. [CrossRef]

117. Bucchiarone, A. Collective Adaptation through Multi-Agents Ensembles: The Case of Smart Urban Mobility. ACM Trans. Auton. Adapt. Syst. 2019, 14. [CrossRef]

118. Poncela, J.; Vlacheas, P.; Giaffreda, R.; De, S.; Vecchio, M.; Nechifor, S.; Barco, R.; Aguayo-Torres, M.C.; Stavroulaki, V.; Moessner, K.; et al. Smart Cities via Data Aggregation. Wirel. Pers. Commun. 2014, 76, 149-168. [CrossRef]

119. Faber, A.; Rehm, S.V.; Hernandez-Mendez, A.; Matthes, F. Modeling and Visualizing Smart City Mobility Business Ecosystems: Insights from a Case Study. Information 2018, 9, 270. [CrossRef]

120. Smart Mobility: Challenges and Solutions in Smart Cities. Available online: https://hub.beesmart. city/en/solutions/smart-mobility/smart-mobility-challenges-and-solutions-in-smart-cities (accessed on 23 August 2020).

121. Fernandez-Ares, A.; Mora, A.; Arenas, M.; Garcia-Sanchez, P.; Romero, G.; Rivas, V.; Castillo, P.; Merelo, J. Studying real traffic and mobility scenarios for a Smart City using a new monitoring and tracking system. Future Gener. Comput. Syst. 2017, 76, 163-179. [CrossRef]

122. Pau, G.; Campisi, T.; Canale, A.; Severino, A.; Collotta, M.; Tesoriere, G. Smart Pedestrian Crossing Management at Traffic Light Junctions through a Fuzzy-Based Approach. Future Internet 2018, 10, 15.

123. Ram, S.; Wang, Y.; Currim, F.; Dong, F.; Dantas, E.; Sabóia, L.A. SMARTBUS: A Web Application for Smart Urban Mobility and Transportation. In WWW'16 Companion: Proceedings of the 25th International Conference Companion on World Wide Web; International World Wide Web Conferences Steering Committee: Montréal, QC, Canada, 2016; pp. 363-368.

124. Bellini, P.; Bilotta, S.; Nesi, P.; Paolucci, M.; Soderi, M. WiP: Traffic Flow Reconstruction from Scattered Data. In Proceedings of the 2018 IEEE International Conference on Smart Computing (SMARTCOMP), Taormina, Italy, 18-20 June 2018; pp. 264-266.

125. Badii, C.; Bellini, P.; Cenni, D.; Difino, A.; Paolucci, M.; Nesi, P. User Engagement Engine for Smart City Strategies. In Proceedings of the 2017 IEEE International Conference on Smart Computing (SMARTCOMP), Hong Kong, China, 29-31 May 2017; pp. 1-7.

126. GrowSmarter-Action Area 3: Sustainable Urban Mobility. Available online: https://grow-smarter.eu/ solutions/sustainable-urban-mobility/ (accessed on 23 August 2020).

127. Smart Urban Mobility-Are We Ready for the Latest Advances in Urban Mobility? Available online: https:/ / www.iberdrola.com/innovation/smart-mobility (accessed on 23 August 2020).

128. Nilssen, M. To the Smart City and Beyond? Developing a Typology of Smart Urban Innovation. Technol. Forecast. Soc. Chang. 2019, 142, 98-104. [CrossRef]

129. The Urban Mobility Daily_What Is Smart Mobility? Available online: https:/ / urbanmobilitydaily.com/ what-is-smart-mobility/ (accessed on 23 August 2020).

130. El Mahrsi, M.K.; Côme, E.; Oukhellou, L.; Verleysen, M. Clustering Smart Card Data for Urban Mobility Analysis. IEEE Trans. Intell. Transp. Syst. 2017, 18, 712-728. [CrossRef]

131. Just Peixoto, J.P.; Costa, D.G. Wireless visual sensor networks for smart city applications: A relevance-based approach for multiple sinks mobility. Future Gener. Comput. Syst. 2017, 76, 51-62. [CrossRef]

132. Zawieska, J.; Pieriegud, J. Smart city as a tool for sustainable mobility and transport decarbonisation. Transp. Policy 2018, 63, 39-50. [CrossRef]

133. Badii, C.; Nesi, P.; Paoli, I. Predicting Available Parking Slots on Critical and Regular Services by Exploiting a Range of Open Data. IEEE Access 2018, 6, 44059-44071. [CrossRef] 
134. Belli, L.; Cirani, S.; Davoli, L.; Melegari, L.; Mónton, M.; Picone, M. An Open-Source Cloud Architecture for Big Stream IoT Applications. In Interoperability and Open-Source Solutions for the Internet of Things: International Workshop, FP7 OpenIoT Project, Held in Conjunction with SoftCOM 2014, Split, Croatia, 18 September 2014, Invited Papers; Podnar Žarko, I., Pripužić, K., Serrano, M., Eds.; Springer International Publishing: Cham, Switzerland, 2015; pp. 73-88.

135. Zyskind, G.; Nathan, O.; Pentland, A. Decentralizing Privacy: Using Blockchain to Protect Personal Data. In Proceedings of the 2015 IEEE Security and Privacy Workshops, San Jose, CA, USA, 18-20 May 2015; pp. 180-184.

136. Biswas, K.; Muthukkumarasamy, V. Securing Smart Cities Using Blockchain Technology. In Proceedings of the 2016 IEEE 18th International Conference on High Performance Computing and Communications, Sydney, Australia, 12-14 December 2016; pp. 1392-1393.

137. Davoli, L.; Belli, L.; Ferrari, G. Enhancing Security in a Big Stream Cloud Architecture for the Internet of Things Through Blockchain. In Applying Integration Techniques and Methods in Distributed Systems and Technologies; IGI Global: Hershey, PA, USA, 2019; pp. 104-133.

138. Smart Cities-Adoption of Future Technologies. Available online: https://worldengineeringday.net/wpcontent/uploads/2020/03/Smart-City-IOT-WFEO-Version-1.pdf (accessed on 22 August 2020).

139. Ok, J.A.; Yoo, S. Directions and improvements of the future smart city development: A case of Gyenggi province. Spat. Inf. Res. 2017, 25, 281-292. [CrossRef]

140. Future of Cities: The Science of Cities and Future Research Priorities. Available online: https://www.gov. uk/government/publications/future-of-cities-science-of-cities(accessed on 22 August 2020).

141. Smart London. Available online: https://www.london.gov.uk/what-we-do/business-and-economy/ supporting-londons-sectors/smart-london (accessed on 21 August 2020).

142. Future City Glasgow. Available online: https://futurecity.glasgow.gov.uk/ (accessed on 21 August 2020).

143. Smart America Project. Available online: https://smartamerica.org/ (accessed on 21 August 2020).

144. Smart City Copenhagen. Available online: https://urbandevelopmentcph.kk.dk/indhold/smart-city (accessed on 21 August 2020).

145. Barcelona Digital City. Available online: https://ajuntament.barcelona.cat/digital/en (accessed on 21 August 2020).

146. Barcelona Institute for Global Health. Saving Lives: Swapping Cars for Shared Bicycles. Available online: https:/ / www.sciencedaily.com/releases/2018/04/180419100210.htm (accessed on 23 August 2020).

147. Biking in Barcelona: How to Use Viu Bicing. Available online: https:/ /www.velabas.com/writing/places / biking-in-barcelona-how-to-use-viu-bicing/ (accessed on 23 August 2020).

148. Smart Mobility 2030 in Singapore. Available online: https://www.lta.gov.sg/content/ltagov/en/getting around/driving_in_singapore/intelligent_transport_systems.html (accessed on 23 August 2020).

149. Nice \& Smart City. Available online: http://business.nicecotedazur.org/en/nice-smart-city-2/ (accessed on 21 August 2020).

150. Thompson, E.M. Smart City: Adding to the Complexity of Cities. In Proceedings of the 34th eCAADe Conference, Oulo, Finland, 22-26 August 2016; Volume 1, pp. 651-660.

151. Amsterdam Smart City. Available online: https://amsterdamsmartcity.com/ (accessed on 21 August 2020).

152. ClairCity_Amsterdam. Available online: http://www.claircity.eu/amsterdam/ (accessed on 21 August 2020).

153. Smart Cities Global Network-Dubai. Available online: https:/ / scgn.smartdubai.ae/ (accessed on 23 July 2020).

154. Fukuoka Smart East. Available online: https:/ / en.smartcity.fukuoka.jp/ (accessed on 21 August 2020).

155. Kitakyushu Smart Community. Available online: https://www.esci-ksp.org/archives/project/kitakyushusmart-community?task_id=915 (accessed on 21 August 2020).

156. FutureCity Yokohama-Yokohama Smart City Project. Available online: https://iuc.eu/japan-en/ bestpractice/yokohama/ (accessed on 21 August 2020).

157. Bhattacharya, S.; Somayaji, S.R.K.; Gadekallu, T.R.; Alazab, M.; Maddikunta, P.K.R. A Review on Deep Learning for Future Smart Cities. Internet Technol. Lett. 2020, 1-6. [CrossRef]

158. Kummitha, R.K.R. Smart Cities and Entrepreneurship: An Agenda for Future Research. Technol. Forecast. Soc. Chang. 2019, 149, 1-10. [CrossRef]

159. Degbelo, A.; Granell, C.; Trilles, S.; Bhattacharya, D.; Casteleyn, S.; Kray, C. Opening up Smart Cities: Citizen-Centric Challenges and Opportunities from GIScience. ISPRS Int. J. Geo-Inf. 2016, 5, 16. [CrossRef] 
160. Cirani, S.; Davoli, L.; Picone, M.; Veltri, L. Performance Evaluation of a SIP-based Constrained Peer-to-Peer Overlay. In Proceedings of the 2014 International Conference on High Performance Computing Simulation (HPCS), Bologna, Italy, 21-25 July 2014; pp. 432-435.

161. Davoli, L.; Protskaya, Y.; Veltri, L. An Anonymization Protocol for the Internet of Things. In Proceedings of the 2017 International Symposium on Wireless Communication Systems (ISWCS), Bologna, Italy, 28-31 August 2017; pp. 459-464.

(C) 2020 by the authors. Licensee MDPI, Basel, Switzerland. This article is an open access article distributed under the terms and conditions of the Creative Commons Attribution (CC BY) license (http:/ / creativecommons.org/licenses/by/4.0/). 